\title{
DENSIFICATION OF ZIRCONIUM NITRIDE BY SPARK PLASMA SINTERING AND HIGH VOLTAGE ELECTRIC DISCHARGE CONSOLIDATION: A COMPARATIVE ANALYSIS
}

\author{
G. Lee $^{1,2}$, M.S. Yurlova ${ }^{3}$, D. Giuntini ${ }^{1,2}$, E.G. Grigoryev ${ }^{3}$, O.L. Khasanov ${ }^{4}$, J. McKittrick $^{2}$, E.A. Olevsky ${ }^{1,3,4, *}$ \\ ${ }^{1}$ Mechanical Engineering, San Diego State University, USA \\ ${ }^{2}$ Mechanical and Aerospace Engineering, University of California, San Diego, USA \\ ${ }^{3}$ Moscow Engineering Physics Institute, Moscow, Russian Federation \\ ${ }^{4}$ National Research Tomsk Polytechnic University, Tomsk, Russian Federation
}

\begin{abstract}
The densification behavior of zirconium nitride powder is investigated for various temperature and pressure conditions imposed by spark plasma sintering and high voltage electric discharge consolidation techniques. The crystal structure, chemical composition, porosity, and grain size of the powders and processed specimens are analyzed by X-ray diffraction, scanning electron microscopy, and energydispersive X-ray spectroscopy. The outcomes of the two considered consolidation techniques are comparatively assessed. Vickers micro-hardness of the processed $\mathrm{ZrN}$ specimens is investigated, and hardness dependence on porosity is analyzed. The densification mechanism of $\mathrm{ZrN}$ consolidated by spark plasma sintering is revealed by applying the constitutive equation of the continuum theory of sintering, and it turns out to be a similar mechanism to hot pressing. Application of the sintering constitutive equations shows that the mechanism of $\mathrm{ZrN}$ densification by high voltage electric discharge consolidation method depends on the magnitude of the applied voltage.
\end{abstract}

Keywords: Zirconium Nitride, Spark Plasma Sintering, Field-Assisted Sintering, High Voltage Electric Discharge Consolidation

*Corresponding author: e-mail: $\underline{\text { eolevsky@ mail.sdsu.edu }}$

(C) 2015. This manuscript version is made available under the Elsevier user license 
Zirconium nitride $(\mathrm{ZrN})$ is a material that has been attracting increasing attention over the last decades, due to the combination of excellent thermal, mechanical and electrical properties, even though there are significant difficulties in its synthesis and processing methodologies. In particular, mechanical strength of $\mathrm{ZrN}$ retained at high temperatures and chemical inertness, with the exception of a limited tendency to oxidize $[1,2]$, render it a suitable material for a variety of applications, such as coatings for thermal barrier layers and tooling setups for material processing. Another application is as a model material for the highly radioactive materials used in nuclear reactors: for fuel pellets (UN) [3, 4], as an inert matrix for actinide fuels [5-7] or as an additive for PuN pellets, with which it can form a solid solution $[8,9]$. However, it is difficult to obtain $\mathrm{ZrN}$ fully dense bodies due to $\mathrm{ZrN}$ high melting temperature $\left(2980^{\circ} \mathrm{C}\right)$, low self-diffusion coefficient $\left(\sim 0.026 \mathrm{~m}^{2} / \mathrm{s}\right.$ at $\left.2400 \sim 2600^{\circ} \mathrm{C}\right)$, strong covalent bonding [10], and the existence of an oxide layer $\left(\mathrm{ZrO}_{2}\right)$ on the surface of the starting powders.

A few studies report on the consolidation of $\mathrm{ZrN}$ powders by sintering or hot pressing (HP), which demonstrated that these methods were not suitable for forming dense, mechanically robust materials $[11,12]$. The best result for sintering in a high purity nitrogen atmosphere at $\sim 2000^{\circ} \mathrm{C}$ for one hour was $95 \%$ relative density with a submicron-sized microstructure [11]. For the hot isostatic pressing (HIP) procedure, 99\% relative density was obtained, which required spherical shape powders and a presintering stage of cold pressing (250 MPa), followed by 2 hours of $\mathrm{HIP}$ at a temperature of $1950^{\circ} \mathrm{C}$ and pressure of $195 \mathrm{MPa}$ [13].

Presently, more efficient $\mathrm{ZrN}$ consolidation methodologies are needed; and promising solutions may be in the more modern electric current-assisted sintering techniques, such as spark plasma sintering (SPS) and high voltage electric discharge consolidation (HVEDC).

SPS is a low-voltage field-assisted sintering method that utilizes an electric current for consolidation of powders under elevated temperature and pressure. A powder specimen placed in an electrically conductive die is subjected to an external pressure applied by electrically conductive punches, 
and the specimen temperature is controlled by Joule heating generated in the die-punch tooling and in the specimen itself, if it is made of an electrically conductive powder material. In comparison with conventional sintering methods, the main advantages of the SPS are lower processing temperature, higher heating rates and shorter holding times - the factors, which usually enable grain size retention [14-18].

In HVEDC, a single pulse of electric current flows through the source powder, leading to an ultraintense energy release inside the powder volume, which is sufficient to allow consolidation up to high density levels for a variety of materials. The high-voltage discharge (up to $30 \mathrm{kV}$ ), obtained by a capacitor bank and released with an extremely short pulse (the pulse length is increase with the applied voltage: 500 $\sim 1300 \mu$ s for $1.5 \sim 5 \mathrm{kV}$ ), creates a significant current density passing through a powder compact, while an external pressure is being applied. As a result, an ultra-rapid temperature increase is attained at the contact points between powder particles and almost instantaneous micro-welding occurs during the electric discharge. Because of such short sintering times, densification is accompanied only by minimal changes in the microstructure, a factor of merit when aiming at achieving high mechanical strength characteristics. During the last decade, this method has attracted growing interest and detailed review can be found in elsewhere [19].

In the past, the mechanical and thermo-electrical characteristics of SPS-processed ZrN samples have been investigated and formulated as functions of porosity and temperature [20,21]. Some more specific analyses of SPS studied the influence of a boron nitride wrapping of powder specimens [22] and the treatment of $\mathrm{W} / \mathrm{ZrN}$ composites [23]. An absence of the modeling-aided analysis of the densification kinetics in these previously conducted studies should be noted. Also, the densification behavior of pure $\mathrm{ZrN}$ and the corresponding mechanical properties has not been reported, and there are no reports on HVEDC processed $\mathrm{ZrN}$ materials.

In the present study, the sinterability and final mechanical properties of the two commercial $\mathrm{ZrN}$ powders processed through the two different field-assisted sintering methods (SPS and HVEDC) have been tested and compared. With fixed holding time and heating rate, a systematic densification map of SPS ZrN was built. Also, the influence of high pressure by double die SPS setup was evaluated. A 
constitutive model of powder hot pressing (based on the continuum theory of sintering [24]) was subsequently applied to the obtained experimental results for the description of the densification kinetics during both SPS and HVEDC.

\section{Materials and processing methods}

\subsection{Materials investigated}

Two ZrN powders (Face centered cubic, Fm3m) were employed for this study, one produced by Sigma Aldrich (SA) and the other by Alfa Aesar (AA). The main powder utilized for the consolidation by both SPS and HVEDC was AA, while SA was utilized for the SPS processing only, in order to compare the behavior of slightly different materials when undergoing this type of electric field-assisted technology.

The powder data are reported in Table 1. The powder morphology and size (Fig. 1) were observed using the scanning electron microscope (SEM) (FEI Quanta 450, USA). The SA powder particles show sharp edges and the absence of agglomeration, while the AA powders are well-rounded, almost spherical particles with a tendency to form agglomerates. The particle size was derived by manual measurements of 90 particles for each powder, resulting in an average value of $6.71 \pm 0.5 \mu \mathrm{m}$ for SA and $6.02 \pm 0.42 \mu \mathrm{m}$ for AA, as shown in Fig. 2.

The crystal structure and lattice parameters were evaluated by X-ray diffraction (XRD) (Bruker D8 diffractometer, MA, USA), utilizing $\mathrm{CuK}_{\alpha}$ radiation at room temperature. In Fig. 3, measured and reference $\mathrm{ZrN}$ (ICSD collection code \# 167851)[25] XRD diffracted plot was drawn by hollow circle and solid line respectively. Also, dashed line shows the intensity difference between the measured and reference peak. Diffracted $(\mathrm{h}, \mathrm{k}, \mathrm{l})$ planes are shown on the top of each peak. From the XRD data, in Fig. 3, the cubic NaCl-type structure dominates, however oxide impurities were found in both powders. Comparing these results with the zirconium oxide peak locations shown in Fig. 3 (a) and (b), the SA powder has oxide in the $\mathrm{Zr}_{3} \mathrm{O}$ form (ICSD Collection code \# 88320) [26], while AA includes $\mathrm{ZrO}_{2}$ (ICSD Collection code \# 66781) [27]. The lattice parameter for the two powders was found to be $0.4563 \mathrm{~nm}$, a value close to what reported in the literature $(0.457 \mathrm{~nm})$ [25]. 


\subsection{Spark plasma sintering processing regimes}

The SPS system utilized was a Dr. Sinter SPSS-515 (SPS Syntex Inc., Japan), with a tooling setup generally constituted by Isocarb Graphite I-85 (Electrodes Inc., CA), except for the selection of silicon carbide for a specific application, as described later.

Fig. 4a shows a schematic diagram of the tooling setup assembly and Fig. 4b shows a photograph of the setup, located in the SPS chamber, before an experimental procedure was run.

Two different pressure conditions were selected. For low-pressure (<90 MPa) experiments, $3.76 \mathrm{~g}$ of powder was placed into a $15.4 \mathrm{~mm}$-diameter graphite die and compressed between two $20 \mathrm{~mm}$-long graphite punches. For the high-pressure (> $90 \mathrm{MPa}$ ) experiments, a double die setup was used [28]. In this case, the tooling additionally had an internal $7 \mathrm{~mm}$-diameter graphite die and two SiC $7 \mathrm{~mm}$-high punches. This double die setup contained $0.82 \mathrm{~g}$ of powder.

A $0.2 \mathrm{~mm}$-thick graphite paper wrapped the powder to prevent adhesion and contamination between the specimen and the tooling. A carbon felt layer, surrounding the graphite die, was used to reduce heat loss. An optical pyrometer (IR-AHS2, Chino, Japan) was used to detect the temperature of the graphite die.

For the SA powders, the measured green densities of the powder compacts were $~ 57 \%, 59 \%$ and $66 \%$, for the pre-SPS cold compaction at $30 \mathrm{MPa}, 60 \mathrm{MPa}$ and $120 \mathrm{MPa}$, respectively. The sintering regime consisted of heating at $100^{\circ} \mathrm{C} / \mathrm{min}$ from room temperature to the maximum temperature (1400, 1500,1600 or $1700^{\circ} \mathrm{C}$ ) with a dwell time of 6 min as represented in Fig. 5. 


\subsection{High voltage electric discharge compaction processing regimes}

As for the materials employed, the information relative to powder AA given in section 2.1 is valid in this case too and will not be reiterated.

The schematic of the apparatus for HVEDC (Impulse-BM, Russia) and a photograph of this setup are shown in Fig. 6 [19]. The overall system consists of the energy storage unit, switch-board, pressure 
and temperature measurement systems, electric current parameters' recording system and powder material sealing registration system. The energy storage unit includes a capacitor bank with a stored energy of 75 $\mathrm{kJ}$, which provides an intense energy discharge to the powder compact and the charging unit. The apparatus uses a pulsed current generated by the capacitor bank, for rapid processing of the powder under constant pressure during the whole process.

The tooling setup employed in the HVEDC procedures consisted of a mold and two molybdenum punches. The mold was a metal cage fixed to an insulating mullite liner with an inner diameter of $10 \mathrm{~mm}$ and an outer diameter of $20 \mathrm{~mm}$. The consolidation of the powders was conducted at pressures of $75 \mathrm{MPa}$ to $300 \mathrm{MPa}$ and at a voltage of $2 \mathrm{kV}$ to $4 \mathrm{kV}$. Measured green densities after applying the pre-sintering pressure ranged from $53.5 \%$ to $61.0 \%$ under pressures of $75 \mathrm{MPa}$ to $300 \mathrm{MPa}$, respectively, as shown in Table 3.

\section{Processed specimen characterization results}

Final density was evaluated, together with the role of temperature and pressure on consolidation, and the influence of porosity on the mechanical and morphological characteristics of the sintered material. The employed technologies and methodologies involved various density measurement techniques, imaging by SEM, analysis by EDS, and hardness obtained from Vickers micro-hardness testing. All measurements were taken at room temperature.

\subsection{Characterization of specimens processed by SPS}

\subsubsection{Sigma Aldrich powders}

The relative density of the SPS specimens was evaluated by means of the Archimedes' immersion method, which required the samples to be coated with paraffin wax prior to the measurements to prevent the access to the open porosity, which resulted in a non-negligible amount of the overall porosity in several specimens. 
All the sintered specimens were fractured or etched and characterized by SEM and EDS. High quality surface was obtained by etching for a few seconds in a solution containing concentrated HF, Aqueous (49\%) / $\mathrm{HNO}_{3}$, Aqueous (70\%) / $\mathrm{H}_{2} \mathrm{O}_{2}$, Aqueous (30\%) with ratio of 4.5:4.5:1 respectively [29].

Vickers micro-hardness tests were performed at room temperature by applying a $1 \mathrm{~kg}$ load on the standard diamond indenter (M-401-H1 Hardness testing machine, Leco, Michigan). A total of 12 indents per specimen from edge to center over the sample cross-section were realized and their diagonal was measured using an optical microscope, so that the Vickers micro-hardness could be calculated as follows:

$$
H V=1.854 \frac{F}{D^{2}}
$$

in which $\mathrm{F}$ is the load (kgf) and $\mathrm{D}$ is the arithmetic mean of the two diagonals (mm).

The physical and mechanical properties of the specimens are listed in Table 3, which showed that the highest values of relative density $(\sim 100 \%)$ were achieved with the SA powder at $1700^{\circ} \mathrm{C}$ under 120 MPa. The final relative densities of these samples are reported in Fig. 7. For a fixed value of pressure, relative density is increased with increasing maximum final temperature with the only exception of the $1700^{\circ} \mathrm{C} / 120 \mathrm{MPa}$ case (explained below). For the temperature and pressure ranges used in this study, these are the highest relative density values attained with a commercial powder. It is worth noting that the powders were not milled and sintering agents were not used. Such relative density values are significantly higher than the $63.5 \%$ we obtained by means of high temperature vertical dilatometer (Unitherm 1161 , Anter coporation, USA), with a maximum sintering temperature of $1500^{\circ} \mathrm{C}$, heating rate of $10^{\circ} \mathrm{C} / \mathrm{min}$ and 2-hours holding time.

One of the main influencing factors during SPS is pressure, whose significant role in powders has been widely investigated [16, 17, 28]. Quach et al. [28] pointed out in yttria-stabilized $\mathrm{ZrO}_{2}$ that pressure prevails diffusional mechanisms at low temperatures, while this trend tends to be less effective once higher temperatures are reached. Analogous conclusions were reached in the present investigation. Fig. 8 plots relative density as a function of temperature. Densification is significantly enhanced when increasing pressure from $30 \mathrm{MPa}$ to $60 \mathrm{MPa}$ at relatively low temperatures $\left(1400^{\circ} \mathrm{C}\right.$ and $\left.1500^{\circ} \mathrm{C}\right)$. 

the relative density. A slightly lower final density was observed for $1500^{\circ} \mathrm{C}$ and $1700^{\circ} \mathrm{C}$ when increasing pressure from $60 \mathrm{MPa}$ to $120 \mathrm{MPa}$. Including previous relative density result of $1700{ }^{\circ} \mathrm{C} / 120 \mathrm{MPa}$ in Fig. 7 , such small decrease could be attributed to measurement errors in the Archimedes' method or to a discrepancy in the application of a high pressure (in this case, $120 \mathrm{MPa}$ ) when using SiC punches instead of the graphite components employed for the low-pressure cases. The SiC punches present lower thermal and electrical conductivity compared with those of graphite, which results in slow heat transfer to specimens compared with regular graphite punches.

Fig. 9(a) shows the relative density as a function of time for a maximum temperature of $1600^{\circ} \mathrm{C}$ for different pressures. The $30 \mathrm{MPa}$ and $60 \mathrm{MPa}$ curves present the same shape, with the latter being shifted to higher values of density, while the $120 \mathrm{MPa}$ case has a different shape. Even though the $120 \mathrm{MPa}$ curve has the highest initial relative density, the corresponding densification rate is lower with respect to the other two cases. Such trend is confirmed by considering the temperature at which the highest densification rate (slope of the curve) is reached for the various levels of pressure. While the 30 and 60 $\mathrm{MPa}$ curves behave as expected, with peak densification rates at $1359^{\circ} \mathrm{C}$ and $1290^{\circ} \mathrm{C}$ respectively, for the $120 \mathrm{MPa}$ one this peak is reached only at $1370^{\circ} \mathrm{C}$. Nevertheless, in both 60 and $120 \mathrm{MPa}$ cases a final relative density of $\sim 99 \%$ is attained, according to the Archimedes' immersion method (Table 4). Fig. 9(b) - (d) shows the microstructure of the fractured specimens consolidated under different pressures of $30 \mathrm{MPa}, 60 \mathrm{MPa}$ and $120 \mathrm{MPa}$ respectively. Generally, an increase of the applied pressure results in the reduction of the grain size of the specimen with the same density [28]. In our results, the 60MPa and 120MPa under $1600{ }^{\circ} \mathrm{C}$ condition have similar density $(\sim 99 \%)$ and grain size $(\sim 24 \mu \mathrm{m})$ (Table 3$)$. This may be attributed to the low thermal conductivity of the SiC punches.

Fig. 10 shows the effect of the maximum sintering temperature on the relative density as a function of time under $60 \mathrm{MPa}$ pressure and shows SEM fractured images of the specimens. Higher sintering temperatures lead to an augment of the final density. As a drawback, the more elevated temperatures promote the increase in grain size from $8.62 \mu \mathrm{m}$ to $33.26 \mu \mathrm{m}$, as shown in the micrographs. Fig. 10(b) 
shows the presence of several open pores for a specimen with $94.55 \%$ final relative density, while solely closed porosity, with voids characterized by small dimensions and a spherical shape, is encountered in the $>\sim 98 \%$-density samples depicted in Fig. 10 (c) - (e).

Fig. 11 shows the grain size dependence on porosity of the SA specimens. The general trend is an increase in grain size with decreasing porosity, with the exception of a few data points. Finally, Vickers micro-hardness measurements were performed. This parameter's dependence on porosity for the SA specimens is shown in Fig. 12(a), revealing a strong correlation. Several previous studies measured the Vickers micro-hardness of $\mathrm{ZrN}$ samples consolidated by SPS [20, 22] or other techniques, such as hot pressing and hot isostatic pressing [7, 13, 30], and reported average values of Vickers micro-hardness between $1000 \mathrm{kgf} / \mathrm{mm}^{2}$ and $1500 \mathrm{kgf} / \mathrm{mm}^{2}$, which is in a good agreement with our data.

\subsubsection{Alfa Aesar powders}

Fig. 11 and Table 4 present the relationship between the porosity and grain size of the AA samples.

Fig. 13 shows the effect of pressure on relative density and also shows the images of fractured specimens sintered at $1700^{\circ} \mathrm{C}$ under four different pressures $(20,120,150$ and $180 \mathrm{MPa})$. Relative density appears to increase with growing pressure, and this influence of pressure is more prominent than that for the SA cases (Fig. 8). It is noted that a maximum relative density of $97.42 \%$ is achieved with highest pressure (180MPa), a value that can be compared with fully dense specimens of SA powders in terms of sinterbility, as shown in Table 4.

Additionally, from the analysis of the microstructure shown in Fig. 13(b)-(e), we notice that pores start to be closed at 93 97\% relative density.

The Vickers micro-hardness measurements outcomes, represented in Fig. 12(b), proved that the hardness dependence on porosity is analogous to the SA case.

\subsection{Characterization of specimens processed by HVEDC}


The relative density of the specimens processed by HVEDC was evaluated by means of hydrostatic weighing in a pycnometer. It is found that the maximum specimen density of $\mathrm{ZrN}$ did not exceed $93 \%$.

Since the governing parameters of the HVEDC technology are pressure and voltage, the densification map describing the density dependence on these two quantities was built and is pictured in Fig. 14. The map is constructed by fitting the experimental data in the test parameters intervals, with an error $<12 \%$. The density of the specimens increases with the load applied in the pre-pressing stage. This trend appears, nevertheless, to have an upper bound. Given a value of electric current, a densification enhancement is observed up to a certain value of cold-pressing load, after which any further increase affects density only slightly. Fig. 14 also shows that the dependence of the relative density on the voltage is linear. The electric power is proportional to the squared voltage. If the voltage is applied for more than a few seconds, the zirconium nitride specimens can reach a thermodynamically stable structure. In this context we expect the $\mathrm{ZrN}$ relative density to depend on the squared voltage. However, the extremely short duration of HVEDC processes leads to kinetically trapped structures, which renders the relative density linearly dependent on the applied voltage. A raise in the electric current density that flows through the powder compact leads to an increase in the density of compacts [31]. However, beyond a certain critical value, the powders will release a significant amount of voltage through the matrix. Quantitatively, the dependence between the energy and the voltage is complex, since the material resistance depends on the relative density of the material, which evolves during processing. In general, the dependences between the process energy and the instant values of system internal parameters, such as density, can be described by rather complex relationships, including exponential / logarithmic terms $[32,33]$. Therefore it may be expected, that if explored over wider ranges of applied voltages, the relationship between the relative density and the voltage may become non-linear.

It should be noted also that for the completeness of the conducted analysis, it is highly desirable to know the temperature of specimens according to the applied voltages. However, in its current apparatus' configuration, the temperature of specimens could not be measured during HVEDC process due to very 
short pulse duration. Theoretically, the correlation between electric discharge parameters and the localized temperature field developed during HVEDC has been analyzed in earlier publications $[19,34]$.

Fig. 15 shows the typical microstructure of a sample prepared under $3 \mathrm{kV}$ and $175 \mathrm{MPa}$ for the (a) (c) and $3 \mathrm{kV}$ and $200 \mathrm{MPa}$ for the (d). Fig. 15(a) shows that the particle size in the center does not exceed the initial values of powder particle size, which indicates an absence of grain growth, as such rapid densification process was expected to guarantee.

On the other hand, the final porosity of the compact with density $>\sim 75 \%$ includes a certain amount of open porosity, primarily located in the peripheral layer (Fig. 15(b)). Having a compact core and a porous periphery may be related to a radially heterogeneous distribution of the green density. This effect is due to a gradient in the lateral pressure caused by the friction of the mold walls against the powder particles movement. The magnitude of this lateral pressure is not constant along the height of the specimen, and it has a tendency to decrease when moving from the punches to the powder, therefore causing a heterogeneous density distribution in the axial direction within the specimen.

A consequence of the uneven distribution of the lateral pressure is a lower green density at the center of the powder compact, combined with a reduced contact area among the particles, which leads to an increased electrical resistivity and therefore enhanced Joule effect and localized peak temperatures.

Apparently with a decrease in the density of electric current (at constant pressure) or the level of applied pressure (at constant current density), the size of the densified central zone is reduced and a corresponding increase in the volume occupied by the porous peripheral zone is obtained, which ultimately leads to a lower overall relative density of the specimen.

An improvement against such non-homogeneities can be reached by applying more elevated (axial) pressures, responsible for the expansion of the dense central zone. If, instead, the current density is increased, the raise in electrical power is focused on the central area. Consequently, localized heating occurs in the region that is already the most compacted, causing a grain size increase in the central zone.

When an electrical current pulse passes through the compact, the peripheral zones can be heated at a temperature relatively lower than the ones in the central part, which results in the friable structure at the 
edge of specimens (Fig. 15(b)). The thickness of the porous layer was reduced by increasing the applied pressure, which can be seen by comparison between Fig. 15(b) and Fig. 15(d).

However, it should be noted that in some areas of the end pressing parts (Fig. 15(c), apparently strong energy is released after formation of the individual grains by dissociation of nitride, constituting eutectic solid solution of zirconium nitride and zirconium (large grains of Fig. 15(d)).

In order to confirm the discussion above, we checked the Vickers micro-hardness measured with a load of $1 \mathrm{kgf}$. These measurements along the longitudinal direction of the samples' cross-section confirmed that the central part was endowed with the most densified material, as shown in Fig. 16(a). The internal area of the specimen exhibits micro-hardness values four times greater than the peripheral areas as shown in Fig. 16(b).

\section{Discussion: processing - structure - properties correlation and modeling of densification kinetics}

\subsection{Processing - structure - properties correlation}

The processing of SA powders resulted in higher relative densities consolidated under SPS compared to AA powders, even though they share similar properties in terms of particle size and distribution. Such behavior can be explained by considering that AA powders are more agglomerated and have higher levels of impurities ( $\mathrm{Hf}<3 \%$ ), which typically hamper the sinterability of this material. Another possible reason may be the higher initial oxygen content in the AA powders. The average composition was $\mathrm{ZrN}_{0.94} \mathrm{O}_{0.11}$ for SA and $\mathrm{ZrN}_{0.99} \mathrm{O}_{0.3} \mathrm{Hf}_{0.01}$ for AA (Table 4), which can be compared with the respective initial compositions of $\mathrm{ZrN}_{0.86} \mathrm{O}_{0.18}$ and $\mathrm{ZrN}_{0.87} \mathrm{O}_{0 .} 28 \mathrm{Hf0.01}$ (Table 1). In both cases the starting powder oxide ratio was retained, which implies that the initial oxide content affects the composition of the densified specimens.

$\mathrm{ZrN}$ is characterized by a broad range of non-stoichiometry $\left(\mathrm{ZrN}_{1-\mathrm{x}}, 0<\mathrm{x}<0.35\right)$. The sintering of $\mathrm{ZrN}$ is accompanied by the release of weekly bound nitrogen $[35,36]$. Interestingly, the application of high pressures makes the nitrogen ratio increase in the AA powders (Table 4). It is inferred that the cold 
pressing with elevated loads prior to the SPS process renders the contact area of the particle larger, which results in reducing the amount of the open pores that act as fast diffusion paths of the dissociated nitrogen. Therefore, nitrogen dissociation is at least partially impeded by a sintering stage of cold pressing.

Both powders share the natural tendency to increase in grain size when porosity is reduced. However, for analogous porosity levels, AA specimens showed a smaller average grain size than SA (Table 4).

Concerning mechanical properties, the specimens' hardness also resulted to be dependent on porosity, as Fig. 12 shows. To evaluate the Vickers hardness of a porous material, the following equation was utilized [37]:

$$
H_{v}(\theta)=H_{v, 0} \times \exp (-b \theta)
$$

where $H_{v, 0}$ is the Vickers hardness of he fully dense material, $b$ is a constant that depends on the applied load and $\theta$ is porosity.

By applying this equation to our hardness data we obtained $b$ and $H_{v, 0}$, which resulted to be 4.22 and 1609.96, respectively, for SA samples and 4.53 and 1633.75 for AA, revealing that the hardness dependence on porosity of the two powders is comparable. The $b$ values are in good agreement with the literature [20].

Because of the high electric currents applied, HVEDC allows consolidation of a powder compact within a few seconds, and therefore the retention in the sintered specimens of smaller grain sizes than in the SPS cases is expected. But, interestingly, the specimens processed by the two techniques share analogous average grain sizes.

The maximum relative densities achieved in the experiments are $\sim 93 \%$ for HVEDC, $\sim 97 \%$ for AA SPS and $\sim 99 \%$ for SA SPS. The lower values attained for the HVEDC cases are explainable by the presence of the porous peripheral zone, while the SPS process renders a more homogeneous microstructure. 
Fig. 16(c) and (d) shows the measurements of the Vickers micro-hardness for the cross-section of the SPS-processed specimens (AA1712 and SA1403) along the longitudinal direction. Compared with Fig. 16(b), which concerns the analogous properties for the HVEDC-processed specimens, the SPS samples present a more uniform structure within the axial cross-section.

Another macro-scale effect of the non-uniformities characterizing HVEDC specimens is found in the presence of cracking and barrel-like shapes in the densified compacts. Additionally, the application of high pressures and voltages create mullite contamination in the samples, The optimal compaction conditions to prevent shape alterations and mullite contamination in the HVEDC of zirconium nitride have been identified in the application of a pressure within the 100 160MPa range and a voltage of $2 \sim 3 \mathrm{kV}$, which, on the other hand, limits the final relative density to $83 \%$.

\subsection{Modeling of the densification kinetics imposed by SPS and HVEDC}

Many efforts are currently dedicated to the individuation and modeling of densification mechanisms of ceramic materials under SPS conditions [32, 38-43], while equations capable of reliable describing consolidation kinetics for HVEDC procedures have not been developed.

In the present study, the constitutive equation of the continuum theory of sintering developed for hot pressing is used to analyze the effect of electric currents on densification kinetics during the SPS and HVEDC processes. Power law creep can be considered the dominant mechanism of densification of crystalline powders $[44,45]$.

The constitutive equation for a non-linear viscous material is [32]:

$$
\sigma_{z}=A_{m} \sqrt{\frac{2}{3} \frac{(1-\theta)}{\theta}}(1-\theta)\left[\sqrt{\frac{2}{3} \frac{(1-\theta)}{\theta}}\left|\frac{\dot{\theta}}{(1-\theta)}\right|\right]^{m}
$$

where $\sigma_{z}$ is the load applied (Pa), $\theta$ is porosity (dimensionless), $\dot{\theta}$ is the porosity change with time (1/s) and $m$ is the strain-rate-sensitivity exponent. The material constant $A_{m}\left(\mathrm{~Pa} \cdot \mathrm{s}^{\mathrm{m}}\right)$, which is a function of 
microstructure (principally reflecting the influences of the grain size, sub-grain size, and dislocation density), is expressed by an Arrhenius-type relationship [46, 47]:

$$
A_{m}=A_{m 0} T^{m} \exp \left(\frac{m \Delta H_{S D}}{R T}\right)
$$

where $A_{m 0}$ is a material's constant $\left(\mathrm{Pa} \cdot(\mathrm{s} / \mathrm{K})^{\mathrm{m}}\right), T$ the absolute temperature $(\mathrm{K}), \Delta H_{S D}$ is the activation energy for self-diffusion $(\mathrm{J} / \mathrm{mol})$, and $\mathrm{R}$ is the gas constant $(\mathrm{J} / \mathrm{mol} \cdot \mathrm{K})$.

Using the Ashby creep equation [45], the sintering mechanism is related with the stress exponent $n$, which is the reciprocal of $m$. Specifically, each creep mechanism corresponds to a certain range of values of $n$ (or $m$ ), as summarized elsewhere [32,48]. Petrykina et al. [49] investigated the hot pressing of $\mathrm{ZrN}$ and found that the underlying creep mechanism consists in dislocation climb $(\mathrm{n}=4 \sim 5, \mathrm{~m}=0.2 \sim 0.25)$ and determined the activation energy for sintering as $142.26 \mathrm{~kJ} / \mathrm{mol}$ [50]. Fig. 17 is a plot of the porosity evolution with time for the SA powder under $1400^{\circ} \mathrm{C}$ and $30 \mathrm{MPa}$ during SPS. The experimental densification curve is displayed by a solid line, while the curves defined by scattered symbols represent the various fitting curves obtained by varying $m$ and $A_{m}$. The best fitting appears to be constituted by the circles traces, corresponding to $A_{m}=2085000\left(\mathrm{~Pa} \cdot \mathrm{s}^{\mathrm{m}}\right)$ and $m=0.22$, indicating that the sintering mechanism of $\mathrm{ZrN}$ under SPS conditions is dislocation climb, analogously to the hot pressing case. It is worth mentioning that in fully dense stoichiometric uranium nitride (UN), which has the same crystallographic structure as $\mathrm{ZrN}$, an analogous value for $m$ was found [51]. Additionally, these results confirm a study conducted by Langer et al. [38-40], who found that the sintering mechanism for ionic conductors, semiconductors or insulating materials did not change between hot pressing and SPS.

For HVEDC, a significant aspect to be taken into account for the modeling of the process is the extreme rapidity characterizing this technique, which allows powders to be consolidated within a few seconds. A "zero-order approximation" of such technology based on its peculiarly short processing time can disregard the influence of heat on densification and, in view of the applied high pressures, can describe HVEDC as a cold pressing process. 
From the constitutive equation for the cold pressing case, the following relationship can be derived [32]:

$$
\sigma_{z}=\sigma_{y} \sqrt{\frac{2}{3} \frac{(1-\theta)^{3}}{\theta}}
$$

where $\sigma_{y}$ is the yield stress of the bulk material.

By substituting the experimental data on pressure and final porosity into Eq. (5), the yield stress for each condition can be calculated, as shown in Fig. 18 (a). It appears that when a low voltage is applied, Eq. (5) provides good correlations with experimental data for a constant value of the yield stress of the bulk material. Indeed, in low voltage processes the short sintering time does not allow enough time for the effect of heating to be significant, and the adoption of a cold pressing model can be considered adequate. When the voltage is increased, the high electrical currents are involved, and the consequent increased heat and/or field-related phenomena, compromise the validity of the purely plastic material assumption, inducing a pressure-dependent behavior on the "apparent yield stress."

The constitutive equation for a non-linear viscous material, Eq. (3), was applied to the HVEDC results to determine the densification mechanism ( $m$ value). Taking the natural logarithm of Eqn. (3) and rearranging,

$$
\ln \sigma_{z}-\frac{1}{2} \ln \frac{2}{3}\left(\frac{1-\theta}{\theta}\right)-(1-\theta)=m\left\{\frac{1}{2} \ln \frac{2}{3} \frac{1}{\theta(1-\theta)}+\ln \dot{\theta}\right\}+\ln A_{m}
$$

After inserting the average porosity rate by calculating slope and pressure given in Fig. 14 into Eq. (6), a plot can be generated to determine $m$ and $A_{m}$, as shown in Fig. 21b. In the conventional sintering theory, the densification of a powder by means of hot pressing provides one $m$ value that is associated with a specific sintering mechanism. However, Fig. 18(b) shows an increase of the slopes ( $m$ value) with increased voltage, if excluding the high pressure points (300MPa for $2.5 \mathrm{kV}$ and $225 \sim 300 \mathrm{MPa}$ for 3 $\sim 4 \mathrm{kV}$ ). Under low voltage, $m=0$, which confirms that HVEDC acts like quasi-cold pressing. Increasing 


\section{Conclusions}

A comparative study of the spark plasma sintering (SPS) and high voltage electric discharge compaction (HVEDC) methods for the consolidation of zirconium nitride $(\mathrm{ZrN})$ was conducted.

SPS allows the obtainment of the highest relative densities and the formation of more uniform microstructures with respect to HVEDC. In this more successful case of SPS, two different ZrN powders were utilized, so that the significant impact of powder agglomeration and oxide content on the physical and mechanical properties of the sintered specimens could be evidenced. Sintering temperature is the critical variable, on the other hand, pressure gives serious effect only with low sintering temperature for the densification of the $\mathrm{ZrN}$ powder (SA). Densification of AA powder depends strongly on the pressure and, nitrogen dissociation from $\mathrm{ZrN}$ was reduced with increasing pressure. Specimens densified by HVEDC have porous structure at the edge and non-uniform shape.

A constitutive model of the densification behavior was proposed and verified based on the experimental data. For SPS, dislocation climb appears to control the consolidation kinetics, while a univocal underlying sintering mechanism could not be individuated for HVEDC in which modeling outcomes are strongly dependent on the applied voltage. It was found that sintering mechanism of $\mathrm{ZrN}$ by SPS is similar to HP, which implies that electric effect of SPS is relatively small compared with the heat effect for the densification of $\mathrm{ZrN}$. Further investigation is necessary in order to perform a more detailed 


\section{Acknowledgements}

The support of the US Department of Energy, Materials Sciences Division, under Award No. DESC0008581, is gratefully acknowledged. JM acknowledges the support of the National Science Foundation, Ceramics Program Grant 1411192 and the Office of Naval Research, Multidisciplinary University Research Initiatives (MURI) Program Grant, FA9550-15-1-0009.

\section{References}

[1] J. Adachi, K. Kurosaki, M. Uno, S. Yamanaka, Thermal and electrical properties of zirconium nitride, J. Alloys Compd., 399 (2005) 242-244.

[2] G.W. Egeland, K. Wheeler, P. Peralta, K.J. McClellan, S.A. Maloy, G.M. Bond, Plastic deformation in zirconium nitride observed by nanoindentation and TEM, J. Nucl. Mater., 416 (2011) 253-261.

[3] K. Wheeler, P. Peralta, M. Parra, K. McClellan, J. Dunwoody, G. Egeland, Effect of sintering conditions on the microstructure and mechanical properties of $\mathrm{ZrN}$ as a surrogate for actinide nitride fuels, J. Nucl. Mater., 366 (2007) 306-316.

[4] H. Muta, K. Kurosaki, M. Uno, S. Yamanaka, Thermal and mechanical properties of uranium nitride prepared by SPS technique, Journal of Materials Science, 43 (2008) 6429-6434.

[5] M. Burghartz, G. Ledergerber, H. Hein, R.R. van der Laan, R.J.M. Konings, Some aspects of the use of $\mathrm{ZrN}$ as an inert matrix for actinide fuels, J. Nucl. Mater., 288 (2001) 233-236.

[6] M. Streit, F. Ingold, Nitrides as a nuclear fuel option, J. Eur. Ceram. Soc., 25 (2005) 2687-2692.

[7] S. Park, I. Han, H. Lee, S. Huh, W. Park, Microstructural evolution and grain morphology of ZrN pellets, Metals and Materials International, 15 (2009) 187-192.

[8] Y. Arai, K. Nakajima, Preparation and characterization of PuN pellets containing ZrN and TiN, J. Nucl. Mater., 281 (2000) 244-247.

[9] A.K. Sengupta, C. Ganguly, (Pu0.7u0.3)N Fuel for Fast Breeder Test Reactor-Thermal Conductivity and Chemical Compatibility with Ss 316 and Sodium, T Indian I Metals, 43 (1990) 31-35.

[10] R.A. Andrievskii, I.I. Spivak, K.L. Chevasheva, Effective self-diffusion coefficients in interstitial compounds, Sov Powder Metall+, 7 (1968) 559-562.

[11] O.V. Pshenichnaya, M.A. Kuzenkova, P.S. Kislyi, The sintering of zirconium nitride in vacuum and in nitrogen, Sov Powder Metall+, 14 (1975) 986-989.

[12] O.V. Pshenichnaya, M.A. Kuzenkova, P.S. Kislyi, Effect of powder particle size on the sintering of zirconium nitride, Sov Powder Metall+, 18 (1979) 882-887.

[13] N. Alexandre, M. Desmaison-Brut, F. Valin, M. Boncoeur, Mechanical properties of hot isostatically pressed zirconium nitride materials, Journal of Materials Science, 28 (1993) 23852390.

[14] E. Khaleghi, Y.-S. Lin, M.A. Meyers, E.A. Olevsky, Spark plasma sintering of tantalum carbide, Scripta Mater., 63 (2010) 577-580. 
[15] Z.A. Munir, U. Anselmi-Tamburini, M. Ohyanagi, The effect of electric field and pressure on the synthesis and consolidation of materials: A review of the spark plasma sintering method, Journal of Materials Science, 41 (2006) 763-777.

[16] Z.A. Munir, D.V. Quach, M. Ohyanagi, Electric Current Activation of Sintering: A Review of the Pulsed Electric Current Sintering Process, J. Am. Ceram. Soc., 94 (2011) 1-19.

[17] J.E. Garay, Current-Activated, Pressure-Assisted Densification of Materials, Annual Review of Materials Research, 40 (2010) 445-468.

[18] R. Orrù, R. Licheri, A.M. Locci, A. Cincotti, G. Cao, Consolidation/synthesis of materials by electric current activated/assisted sintering, Materials Science and Engineering: R: Reports, 63 (2009) 127-287.

[19] M.S. Yurlova, V.D. Demenyuk, L.Y. Lebedeva, D.V. Dudina, E.G. Grigoryev, E.A. Olevsky, Electric pulse consolidation: an alternative to spark plasma sintering, Journal of Materials Science, 49 (2014) 952-985.

[20] J. Adachi, K. Kurosaki, M. Uno, S. Yamanaka, Porosity influence on the mechanical properties of polycrystalline zirconium nitride ceramics, J. Nucl. Mater., 358 (2006) 106-110.

[21] J. Adachi, K. Kurosaki, M. Uno, S. Yamanaka, Effect of porosity on thermal and electrical properties of polycrystalline bulk $\mathrm{ZrN}$ prepared by spark plasma sintering, J. Alloys Compd., 432 (2007) 7-10.

[22] Y. Tang, J.-X. Xue, G.-J. Zhang, X.-G. Wang, C.-M. Xu, Microstructural differences and formation mechanisms of spark plasma sintered ceramics with or without boron nitride wrapping, Scripta Mater., 75 (2014) 98-101.

[23] D. Lee, M.A. Umer, Y. Shin, S. Jeon, S. Hong, The effect of sintering conditions and $\mathrm{ZrN}$ volume fraction on the mechanical properties of spark plasma sintered W/ZrN composites, Mat Sci Eng aStruct, 552 (2012) 481-485.

[24] E.A. Olevsky, Theory of sintering: from discrete to continuum, Materials Science and Engineering: R: Reports, 23 (1998) 41-100.

[25] W. Chen, J.Z. Jiang, Elastic properties and electronic structures of 4d- and 5d-transition metal mononitrides, J. Alloys Compd., 499 (2010) 243-254.

[26] A.B. Riabov, V.A. Yartys, B.C. Hauback, P.W. Guegan, G. Wiesinger, I.R. Harris, Hydrogenation behaviour, neutron diffraction studies and microstructural characterisation of boron oxide-doped Zr-V alloys, J. Alloys Compd., 293-295 (1999) 93-100.

[27] B. Bondars, G. Heidemane, J. Grabis, K. Laschke, H. Boysen, J. Schneider, F. Frey, Powder diffraction investigations of plasma sprayed zirconia, Journal of Materials Science, 30 (1995) 16211625.

[28] D.V. Quach, H. Avila-Paredes, S. Kim, M. Martin, Z.A. Munir, Pressure effects and grain growth kinetics in the consolidation of nanostructured fully stabilized zirconia by pulsed electric current sintering, Acta Mater., 58 (2010) 5022-5030.

[29] P.T. Dawson, Auger and x-ray characterization of surface nitride films on Ti, Zr, and Hf, Journal of Vacuum Science and Technology, 21 (1982) 36.

[30] X.J. Chen, V.V. Struzhkin, Z. Wu, M. Somayazulu, J. Qian, S. Kung, A.N. Christensen, Y. Zhao, R.E. Cohen, H.K. Mao, R.J. Hemley, Hard superconducting nitrides, Proceedings of the National Academy of Sciences of the United States of America, 102 (2005) 3198-3201.

[31] E.V. Aleksandrova, A.M. Ilyina, E.G. Grigoryev, E.A. Olevsky, Contribution of electric current into densification kinetics during spark-plasma sintering of conductive powder, J. Am. Ceram. Soc., (2015) in press.

[32] W. Li, E.A. Olevsky, J. McKittrick, A.L. Maximenko, R.M. German, Densification mechanisms of spark plasma sintering: multi-step pressure dilatometry, Journal of Materials Science, 47 (2012) 7036-7046.

[33] E.A. Olevsky, B. Kushnarev, A. Maximenko, V. Tikare, M. Braginsky, Modelling of anisotropic sintering in crystalline ceramics, Philos Mag, 85 (2005) 2123-2146. 
[34] E.G. Grigoryev, E.A. Olevsky, Thermal processes during high-voltage electric discharge consolidation of powder materials, Scripta Mater., 66 (2012) 662-665.

[35] M.E. Straumanis, C.A. Faunce, W.J. James, The Defect Structure and Bonding of Zirconium Nitride Containing Excess Nitrogen, Inorg. Chem., 5 (1966) 2027-2030.

[36] Y. Tang, G.-J. Zhang, J.-X. Xue, X.-G. Wang, C.-M. Xu, X. Huang, Densification and mechanical properties of hot-pressed ZrN ceramics doped with Zr or Ti, J. Eur. Ceram. Soc., 33 (2013) 13631371.

[37] J. Luo, R. Stevens, Porosity-dependence of elastic moduli and hardness of 3Y-TZP ceramics, Ceram. Int., 25 (1999) 281-286.

[38] E. Olevsky, L. Froyen, Constitutive modeling of spark-plasma sintering of conductive materials, Scripta Mater., 55 (2006) 1175-1178.

[39] E.A. Olevsky, L. Froyen, Impact of Thermal Diffusion on Densification During SPS, J. Am. Ceram. Soc., 92 (2009) S122-S132.

[40] B. McWilliams, A. Zavaliangos, K. Cho, R. Dowding, The modeling of electric-current-assisted sintering to produce bulk nanocrystalline tungsten, JOM, 58 (2006) 67-71.

[41] J. Langer, M.J. Hoffmann, O. Guillon, Direct comparison between hot pressing and electric fieldassisted sintering of submicron alumina, Acta Mater., 57 (2009) 5454-5465.

[42] J. Langer, M.J. Hoffmann, O. Guillon, Electric Field-Assisted Sintering and Hot Pressing of Semiconductive Zinc Oxide: A Comparative Study, J. Am. Ceram. Soc., 94 (2011) 2344-2353.

[43] J. Langer, M.J. Hoffmann, O. Guillon, Electric Field-Assisted Sintering in Comparison with the Hot Pressing of Yttria-Stabilized Zirconia, J. Am. Ceram. Soc., 94 (2011) 24-31.

[44] K.L. Johnson, The correlation of indentation experiments, Journal of the Mechanics and Physics of Solids, 18 (1970) 115-126.

[45] D.S. Wilkinson, M.F. Ashby, Pressure sintering by power law creep, Acta Metall., 23 (1975) 12771285.

[46] E.A. Olevsky, C. Garcia-Cardona, W.L. Bradbury, C.D. Haines, D.G. Martin, D. Kapoor, S.J. Kang, Fundamental Aspects of Spark Plasma Sintering: II. Finite Element Analysis of Scalability, J. Am. Ceram. Soc., 95 (2012) 2414-2422.

[47] D. Giuntini, E. Olevsky, C. Garcia-Cardona, A. Maximenko, M. Yurlova, C. Haines, D. Martin, D. Kapoor, Localized Overheating Phenomena and Optimization of Spark-Plasma Sintering Tooling Design, Materials, 6 (2013) 2612-2632.

[48] T.G. Nieh, J. Wadsworth, O.D. Sherby., Superplasticity in Metals and Ceramics, Cambridge University Press 1997.

[49] R.Y. Petrykina, L.K. Shvedova, Hot pressing of transition metal nitrides and their properties, Sov Powder Metall+, 11 (1972) 276-279.

[50] M.S. Koval'chenko, R.Y. Petrykina, G.V. Samsonov, Densification of niobium powder in hot pressing, Sov Powder Metall+, 8 (1969) 696-699.

[51] S.L. Hayes, J.K. Thomas, K.L. Peddicord, Material property correlations for uranium mononitride: III. Transport properties, J. Nucl. Mater., 171 (1990) 289-299. 


\section{Table Captions}

Table 1. ZrN powders' characteristics.

Table 2. $\quad$ Energy-dispersive X-ray spectroscopy results of SA and AA powders.

Table 3. Green density of AA specimens after applying the pressure for the high voltage electric discharge consolidation.

Table 4. Physical, chemical and mechanical properties of $\mathrm{ZrN}$ (SA and AA) specimens prepared by spark plasma sintering.

\section{Figure Captions}

Fig. 1. As-received $\mathrm{ZrN}$ powders, (a),(b) SA and (c),(d) AA powders.

Fig. 2. Particle size distribution of the ZrN powders, (a) SA and (b) AA powders.

Fig. 3. X-ray diffraction results of SA (a) and AA powders (b), arrows indicate the oxide impurity positions. $\mathrm{Zr} 3 \mathrm{O}$ (a) and $\mathrm{ZrO} 2$ (b) peak location and relative intensity were shown at the bottom of each plot.

Fig. 4. (a) Schematic representation of spark plasma sintering process, (b) spark plasma sintering machine before an experiment.

Fig. 5. Temperature regime for the consolidation of $\mathrm{ZrN}$ (SA) powders by spark plasma sintering process.

Fig. 6. (a) Schematic representation of high voltage electric discharge consolidation process, (b) high voltage electric discharge consolidation machine before an experiment [19].

Fig. 7. Relative density plot of $\mathrm{ZrN}$ (SA) specimens prepared by spark plasma sintering measured by Archimedes immersion method.

Fig. 8. Effect of the pressure on the final relative density of SPSed $\mathrm{ZrN}$ (SA) specimens sintered at different temperature.

Fig. 9. Relative density variation with time at fixed maximum temperature of $1600{ }^{\circ} \mathrm{C}$ and scanning electron microscope image of SPSed $\mathrm{ZrN}$ (SA) specimens (b) $30 \mathrm{MPa}$, (c) $60 \mathrm{MPa}$ and (d) 120MPa.

Fig. 10. Relative density variation with time at fixed pressure of $60 \mathrm{MPa}$ and scanning electron microscope image of the fracture surface of SPSed $\mathrm{ZrN}$ (SA) : (b) $1400{ }^{\circ} \mathrm{C}$, (c) $1500{ }^{\circ} \mathrm{C}$, (d) $1600{ }^{\circ} \mathrm{C}$ and (e) $1700{ }^{\circ} \mathrm{C}$. Open and closed pores are indicated by white arrows. 
Fig. 11. Grain size dependence on porosity of SA and AA specimens consolidated by spark plasma sintering. $1400 \sim 1700{ }^{\circ} \mathrm{C}, 30 \sim 120 \mathrm{MPa}$ for SA specimens and $1700{ }^{\circ} \mathrm{C}, 0 \sim 180 \mathrm{MPa}$ for AA specimens.

Fig. 12. Vickers microhardness dependence on porosity of $\mathrm{ZrN}$ specimens (a,b) SA, AA consolidated by spark plasma sintering and (c) AA consolidated by high voltage electric discharge consolidation.

Fig. 13. Relative density variation with pressure at fixed maximum temperature of $1700^{\circ} \mathrm{C}$ (a) and SEM image of (b) $20 \mathrm{MPa}$, (c) $120 \mathrm{MPa}$, (d) $150 \mathrm{MPa}$ and (e) $180 \mathrm{MPa}$ for the $\mathrm{ZrN}$ (AA) consolidated by spark plasma sintering. Open and closed pores are indicated by white arrows.

Fig. 14. The densification map of $\mathrm{ZrN}$ (AA) consolidated by high voltage electric discharge consolidation. The relative density of the specimens is given as a function of pressure and voltage. The legend indicates the relative density.

Fig. 15. Scanning electron microscope images of $\mathrm{ZrN}$ (AA) specimens consolidated by high voltage electric discharge consolidation. (a) central and((b) and (c)) edge of the specimen $(3 \mathrm{kV}$ and $175 \mathrm{MPa})$ and $(\mathrm{d})$ edge of the specimen $(3 \mathrm{kV}$ and $200 \mathrm{MPa})$.

Fig. 16. Vickers micro-hardness results of $\mathrm{ZrN}$ specimens after sectioning, (a) schematics of the analyzed areas, from edge (Location 1) to center( location 3), Vickers micro-hardness plot as a function of the radial position of (b) AA specimen consolidated by high voltage electric discharge consolidation, (c) AA specimen consolidated by spark plasma sintering and (d) SA specimen consolidated by spark plasma sintering.

Fig. 17. Constitutive equation fitting of experimental porosity curves of $\mathrm{ZrN}$ (SA) specimen (SA1403) prepared by spark plasma sintering.

Fig. 18. Constitutive equation fitting of high voltage electric discharge consolidation results. (a) yield stress variation with pressure and (b) m variation with voltage. 
Table 1. ZrN powders' characteristics

\begin{tabular}{|l|c|c|}
\hline Name & SA* & AA** \\
\hline Vendor & Sigma Aldrich & Alfa Aesar \\
\hline Lot \# & BCBC1256V $27 X 042$ \\
\hline Purity & $\geq 99 \%$ (trace metals basis) & $\begin{array}{c}\text { H9.5\% (metal basis excluding } \\
\text { Hf }<3 \%\end{array}$ \\
\hline Size & Particle size: $6.71 \pm 0.5 \mu \mathrm{m}$ & $\begin{array}{c}\text { Particle size: } 6.02 \pm 0.42 \mu \mathrm{m} \\
\text { Melting temperature }\left({ }^{\circ} \mathbf{C}\right)\end{array}$ \\
\hline Composition & 2980 & 2980 \\
\hline
\end{tabular}

* Sintered by spark plasma sintering

** Sintered by spark plasma sintering and high voltage electric discharge consolidation 
Table 2.Energy-dispersive X-ray spectroscopy results of SA and AA powders

\begin{tabular}{|c|c|c|c|}
\hline Element & Shell & SA & AA \\
\hline $\mathbf{N}$ & $\mathrm{K}$ & $42.26 \%$ & $40.19 \%$ \\
\hline $\mathbf{O}$ & $\mathrm{K}$ & $8.72 \%$ & $13.03 \%$ \\
\hline $\mathbf{Z r}$ & $\mathrm{L}$ & $49.02 \%$ & $46.26 \%$ \\
\hline $\mathbf{H f}$ & $\mathrm{M}$ & $0 \%$ & $0.53 \%$ \\
\hline
\end{tabular}


Table 3. Green density of AA specimens after applying the pressure for the high voltage electric discharge consolidation

\begin{tabular}{|l|c|c|c|c|c|c|c|c|c|c|}
\hline Pressure (MPa) & 75 & 100 & 125 & 150 & 175 & 200 & 225 & 250 & 275 & 300 \\
\hline Green relative density (\%) & 53.5 & 54.5 & 56 & 57 & 58 & 59 & 60.5 & 60.5 & 61 & 61 \\
\hline
\end{tabular}


Table 4. Physical, chemical and mechanical properties of $\mathrm{ZrN}$ (SA and AA) specimens prepared by spark plasma sintering

\begin{tabular}{|c|c|c|c|c|c|c|}
\hline Specimen & $\begin{array}{c}\text { Sintering } \\
\text { temperature }\left({ }^{\circ} \mathrm{C}\right)\end{array}$ & $\begin{array}{c}\text { Sintering } \\
\text { pressure } \\
\text { (MPa) }\end{array}$ & $\begin{array}{l}\text { Relative density } \\
\text { (\%, Archimedes ) }\end{array}$ & $\begin{array}{c}\text { Grain } \\
\text { Size }(\mu \mathrm{m})\end{array}$ & $\mid \begin{array}{c}\mathrm{HV1} \\
\left(\mathrm{kgf} / \mathrm{mm}^{2}\right)\end{array}$ & $\begin{array}{l}\text { Composition } \\
\text { (Atom \%) }\end{array}$ \\
\hline SA1403 & 1400 & 30 & 89.73 & 6.99 & 959.59 & $\mathrm{ZrN}_{0.76} \mathrm{O}_{0.10}$ \\
\hline SA1503 & 1500 & 30 & 93.18 & 12.47 & 1234.02 & $\mathrm{ZrN}_{0.87} \mathrm{O}_{0.11}$ \\
\hline SA1603 & 1600 & 30 & 95.36 & 17.59 & 1435.89 & $\mathrm{ZrN}_{1.03} \mathrm{O}_{0.13}$ \\
\hline SA1703 & 1700 & 30 & 98.34 & 32.70 & 1413.85 & $\mathrm{ZrN}_{0.88} \mathrm{O}_{0.10}$ \\
\hline SA1406 & 1400 & 60 & 94.55 & 8.62 & 1249.33 & $\mathrm{ZrN}_{0.93} \mathrm{O}_{0.11}$ \\
\hline SA1506 & 1500 & 60 & 98.51 & 17.47 & 1561.46 & $\mathrm{ZrN}_{0.94} \mathrm{O}_{0.10}$ \\
\hline SA1606 & 1600 & 60 & 98.94 & 24.67 & 1507.16 & $\mathrm{ZrN}_{0.90} \mathrm{O}_{0.10}$ \\
\hline SA1706 & 1700 & 60 & 99.52 & 33.26 & 1528.58 & $\mathrm{ZrN}_{0.88} \mathrm{O}_{0.10}$ \\
\hline SA1412 & 1400 & 120 & 96.22 & 9.14 & 1419.09 & $\mathrm{ZrN}_{1.21} \mathrm{O}_{0.14}$ \\
\hline SA1512 & 1500 & 120 & 97.90 & 16.71 & 1473.06 & $\mathrm{ZrN}_{0.81} \mathrm{O}_{0.10}$ \\
\hline SA1612 & 1600 & 120 & 99.12 & 24.09 & 1480.54 & $\mathrm{ZrN}_{1.15} \mathrm{O}_{0.13}$ \\
\hline SA1712 & 1700 & 120 & 98.12 & 22.79 & 1498.11 & $\mathrm{ZrN}_{0.89} \mathrm{O}_{0.10}$ \\
\hline AA1700 & 1700 & 0 & 54.07 & - & - & - \\
\hline AA1702 & 1700 & 20 & 75.58 & 3.61 & 546.30 & $\mathrm{ZrN}_{0.82} \mathrm{O}_{0.17} \mathrm{Hf}_{0.01}$ \\
\hline AA1712 & 1700 & 120 & 93.19 & 3.77 & 1183.6 & $\mathrm{ZrN}_{0.90} \mathrm{O}_{0.36} \mathrm{Hf}_{0.01}$ \\
\hline AA1715 & 1700 & 150 & 96.95 & 5.99 & 1446.71 & $\mathrm{ZrN}_{1.06} \mathrm{O}_{0.37} \mathrm{Hf}_{0.01}$ \\
\hline AA1718 & 1700 & 180 & 97.42 & 6.30 & 1422.46 & $\mathrm{ZrN}_{1.16} \mathrm{O}_{0.31} \mathrm{Hf}_{0.02}$ \\
\hline
\end{tabular}



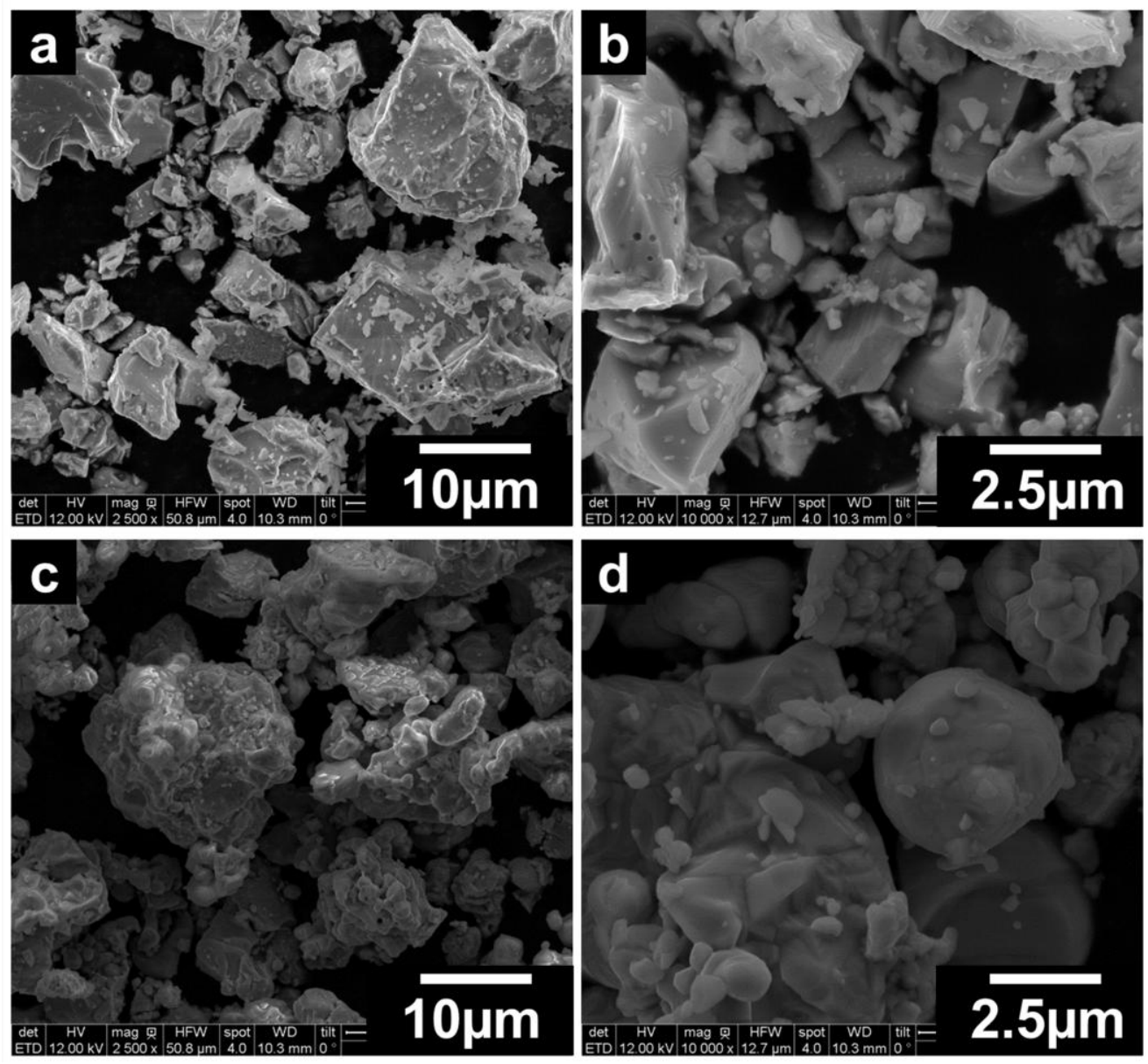

Fig. 1. As-received $\mathrm{ZrN}$ powders, (a),(b) SA and (c),(d) AA powders. 

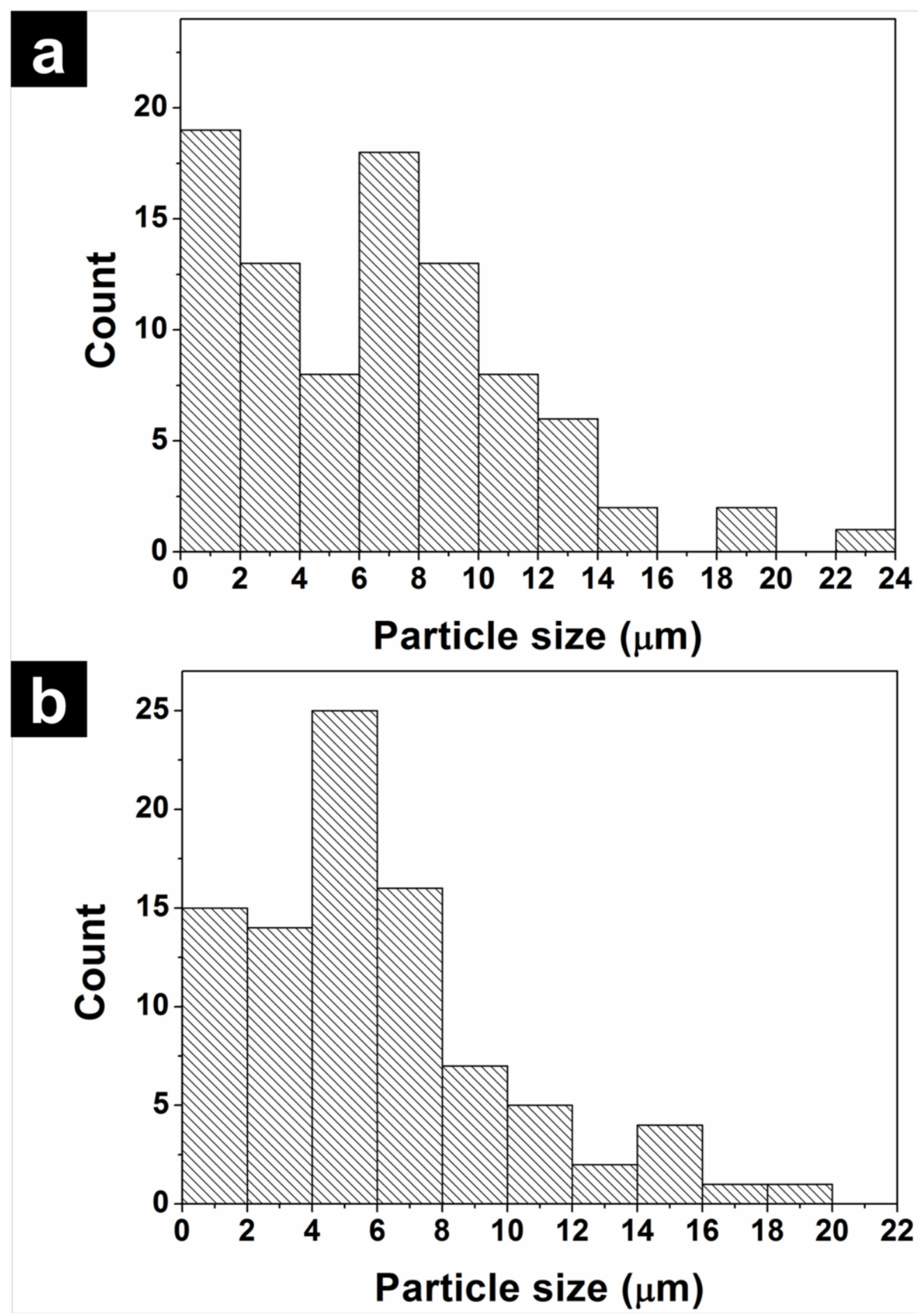

Fig. 2. Particle size distribution of the $\mathrm{ZrN}$ powders, (a) SA and (b) AA powders. 

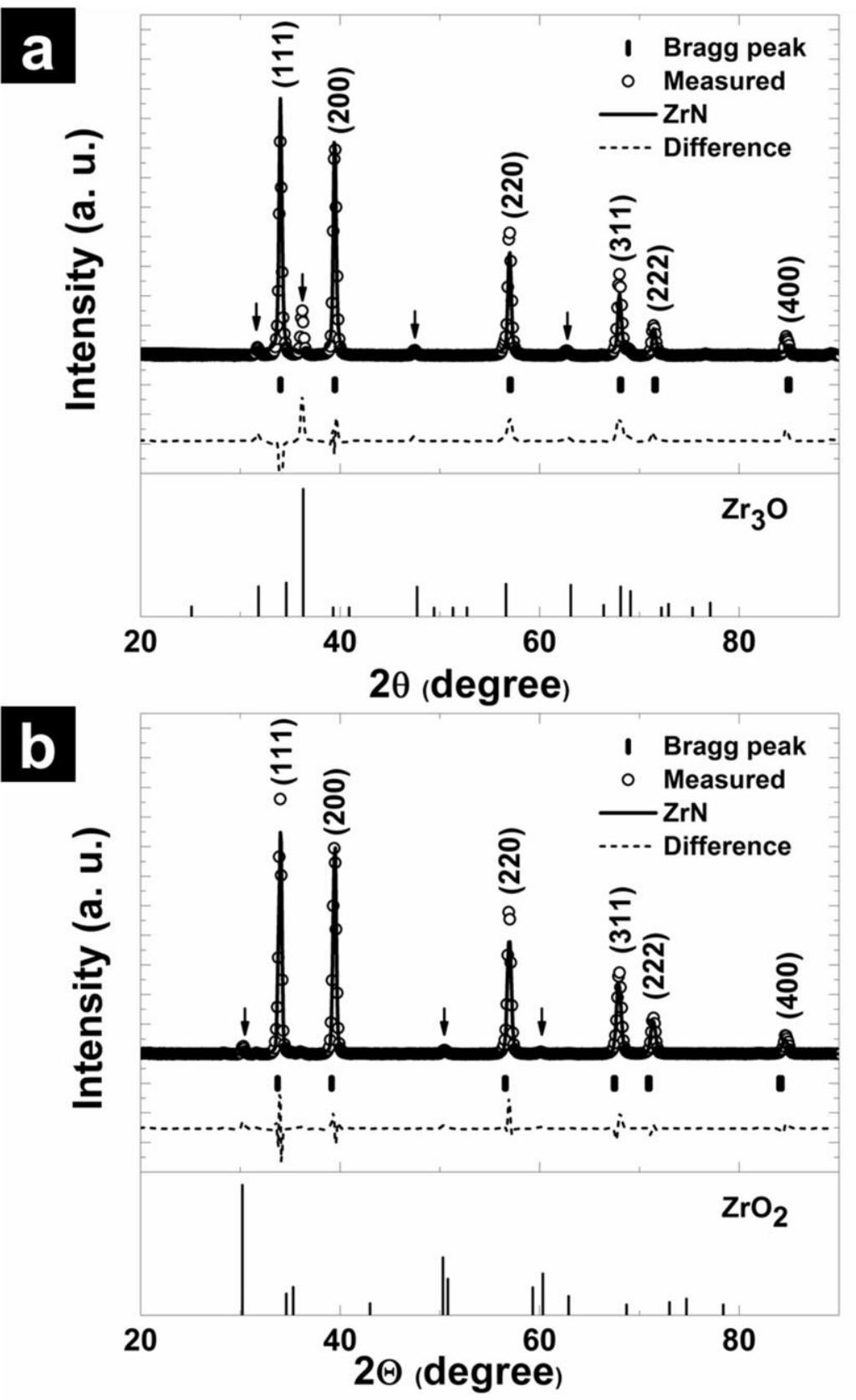

Fig. 3. X-ray diffraction results of SA (a) and AA powders (b), arrows indicate the oxide impurity positions. $\mathrm{Zr} 3 \mathrm{O}$ (a) and $\mathrm{ZrO} 2$ (b) peak location and relative intensity were shown at the bottom of each plot. 


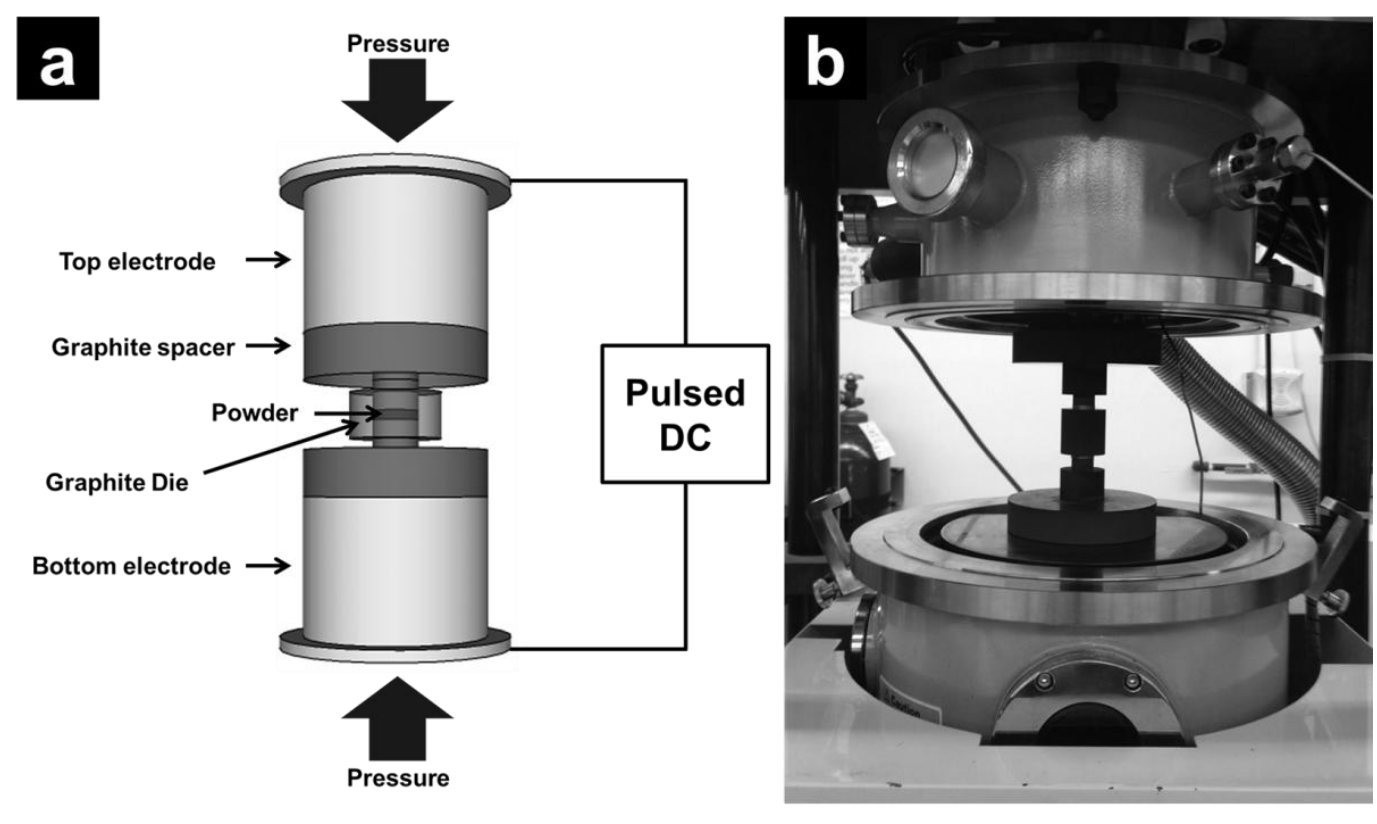

Fig. 4. (a) Schematic representation of spark plasma sintering process, (b) spark plasma sintering machine before an experiment. 


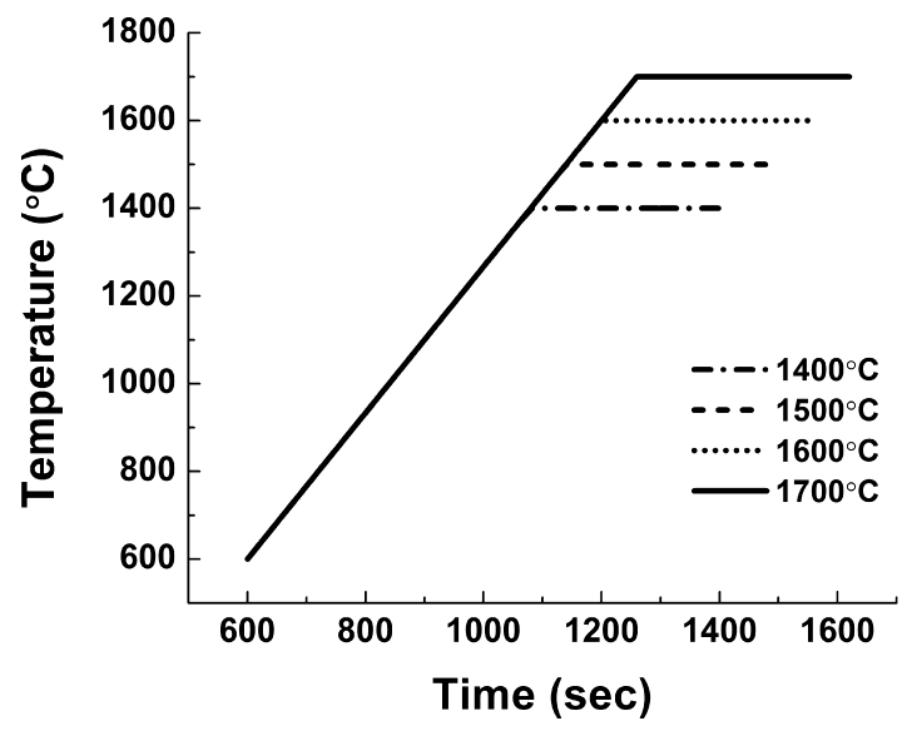

Fig. 5. Temperature regime for the consolidation of $\mathrm{ZrN}$ (SA) powders by spark plasma sintering process. 

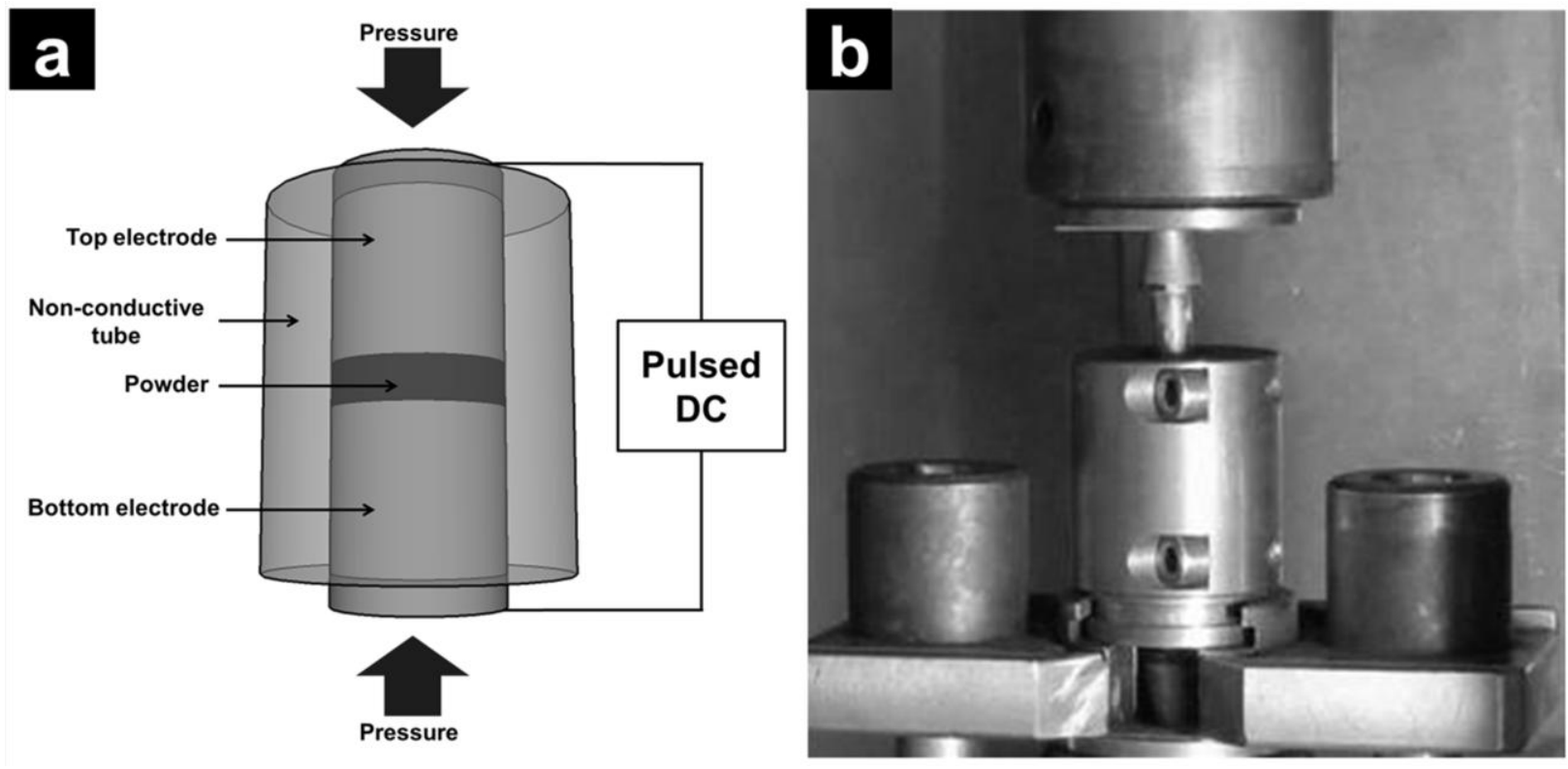

Fig. 6. (a) Schematic representation of high voltage electric discharge consolidation process, (b) high voltage electric discharge consolidation machine before an experiment [19]. 


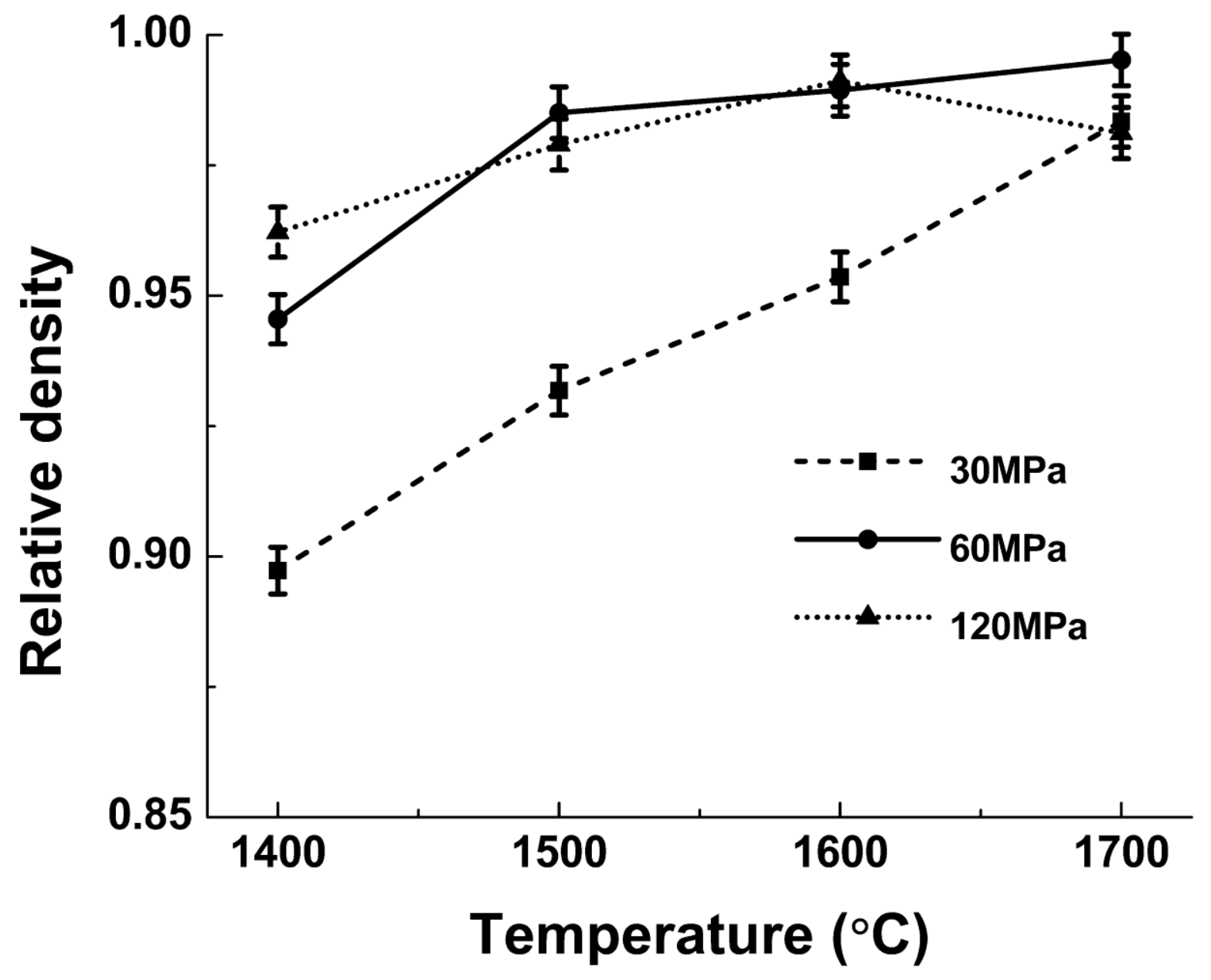

Fig. 7. Relative density plot of $\mathrm{ZrN}$ (SA) specimens prepared by spark plasma sintering measured by Archimedes immersion method. 


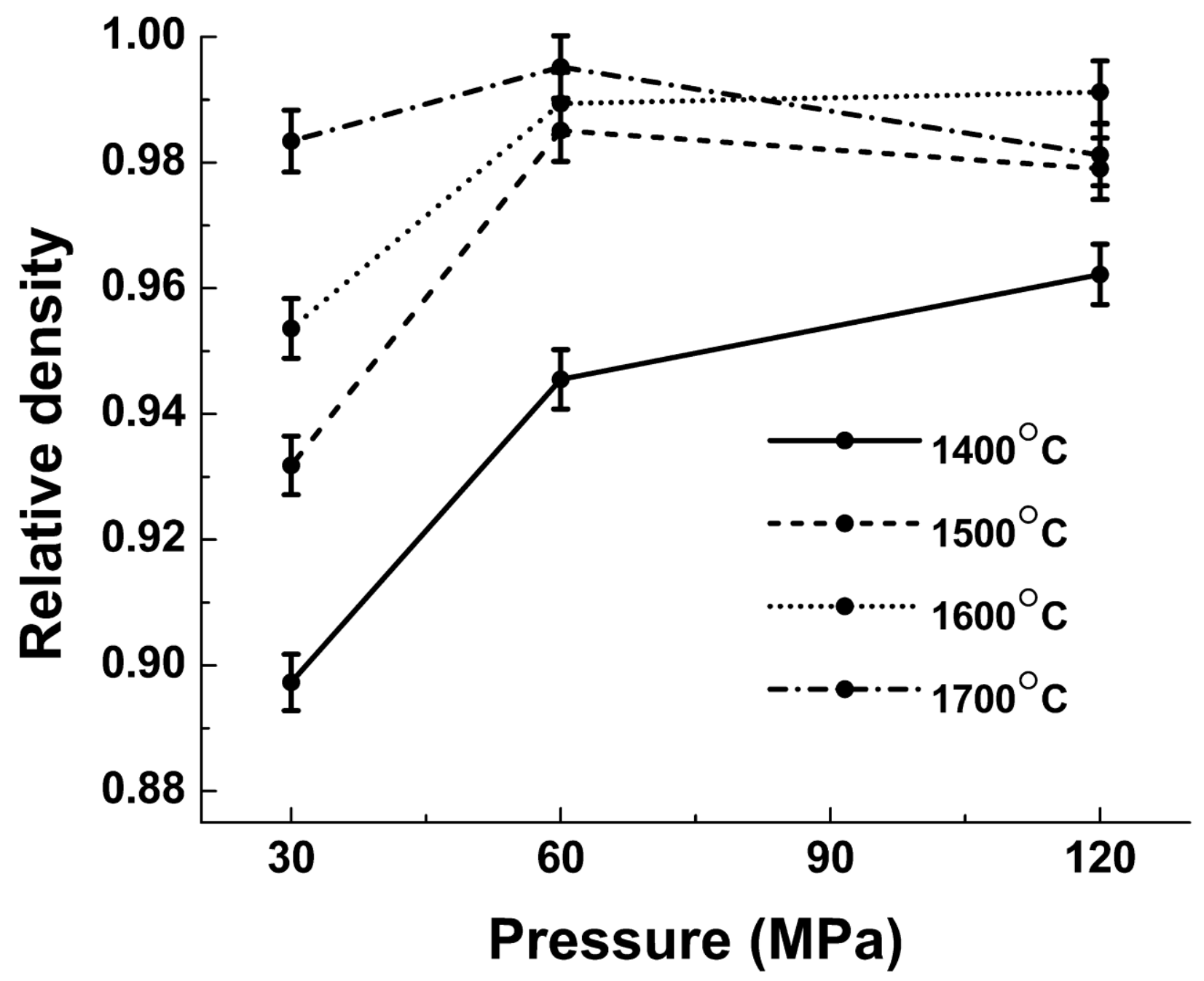

Fig. 8. Effect of the pressure on the final relative density of SPSed $\mathrm{ZrN}$ (SA) specimens sintered at different temperature. 

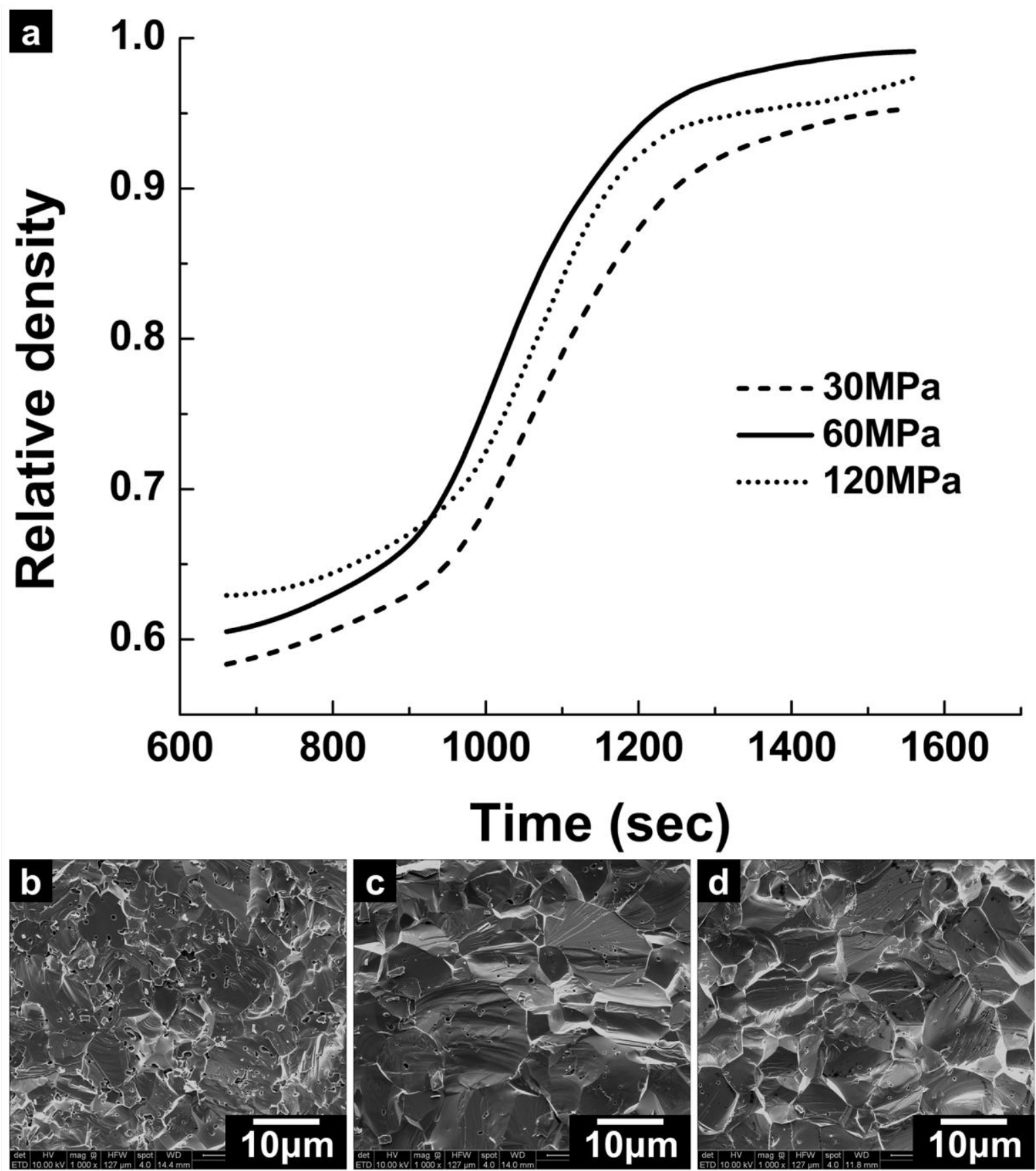

Fig. 9. Relative density variation with time at fixed maximum temperature of $1600{ }^{\circ} \mathrm{C}$ and scanning electron microscope image of SPSed ZrN (SA) specimens (b) $30 \mathrm{MPa}$, (c) $60 \mathrm{MPa}$ and (d) $120 \mathrm{MPa}$. 

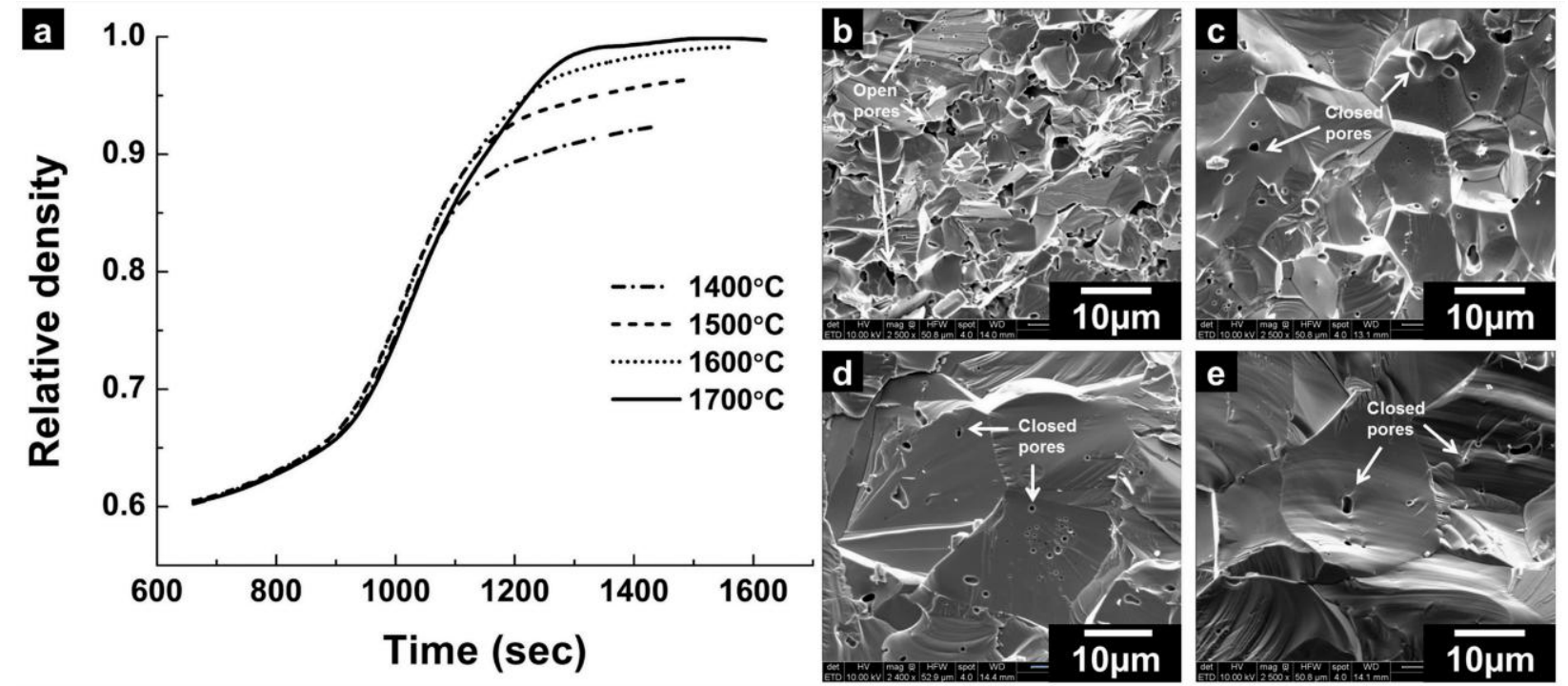

Fig. 10. Relative density variation with time at fixed pressure of $60 \mathrm{MPa}$ and scanning electron microscope image of the fracture surface of SPSed $\mathrm{ZrN}$ (SA) : (b) $1400{ }^{\circ} \mathrm{C}$, (c) $1500{ }^{\circ} \mathrm{C}$, (d) $1600{ }^{\circ} \mathrm{C}$ and (e) $1700{ }^{\circ} \mathrm{C}$. Open and closed pores are indicated by white arrows. 


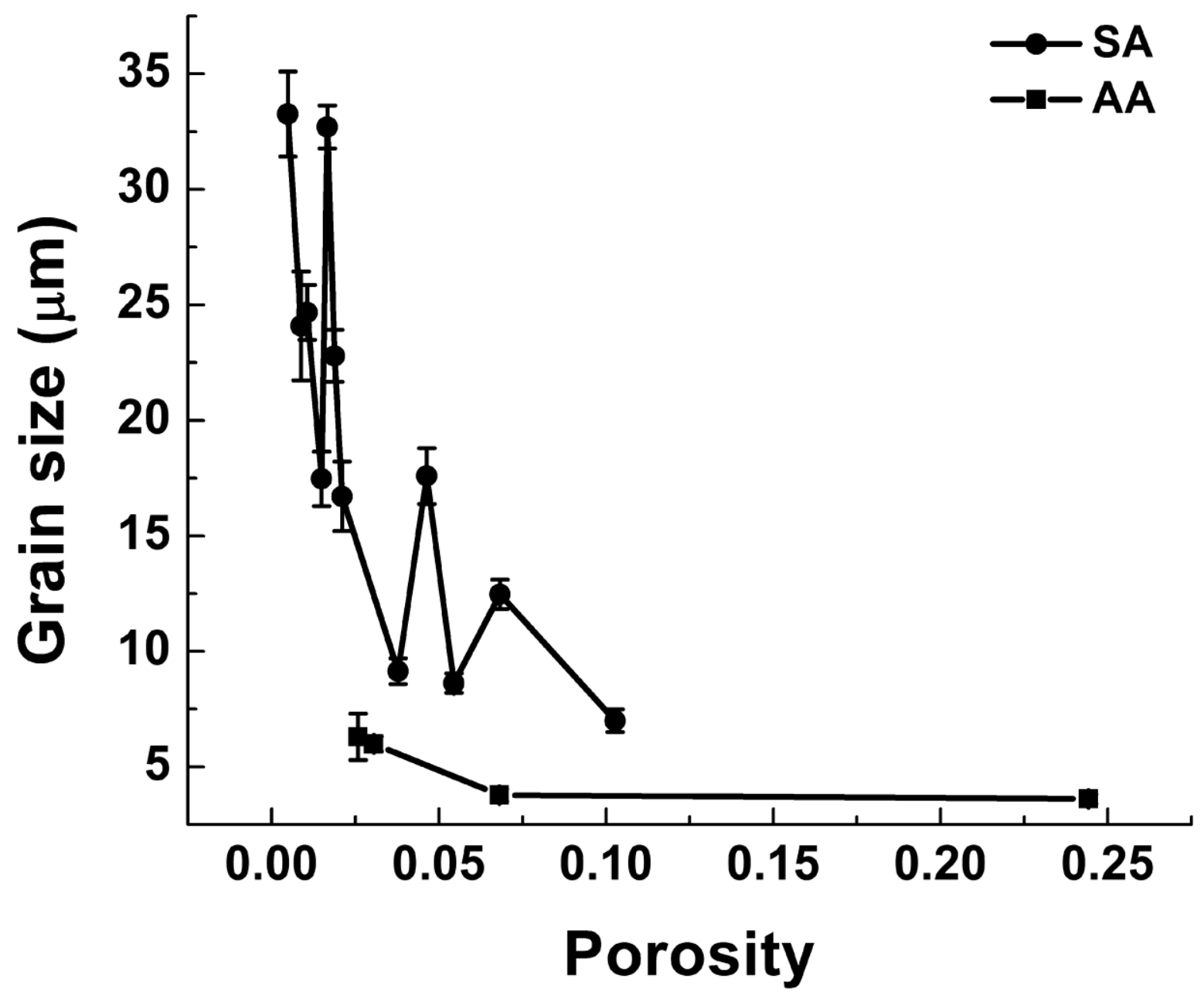

Fig. 11. Grain size dependence on porosity of SA and AA specimens consolidated by spark plasma sintering. $1400 \sim 1700{ }^{\circ} \mathrm{C}, 30 \sim 120 \mathrm{MPa}$ for SA specimens and $1700{ }^{\circ} \mathrm{C}, 0 \sim 180 \mathrm{MPa}$ for AA specimens. 

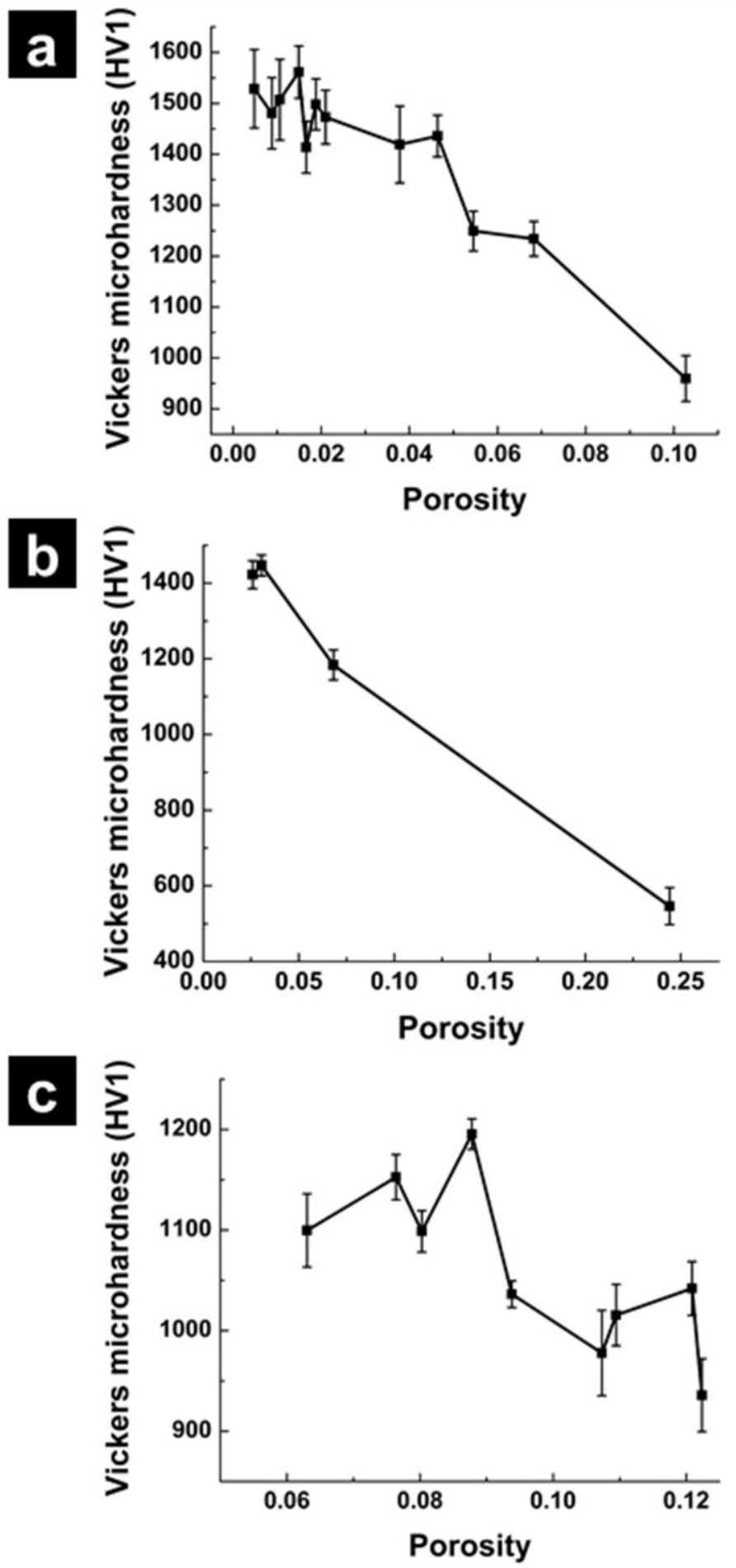

Fig. 12. Vickers microhardness dependence on porosity of $\mathrm{ZrN}$ specimens (a,b) SA, AA consolidated by spark plasma sintering and (c) AA consolidated by high voltage electric discharge consolidation. 

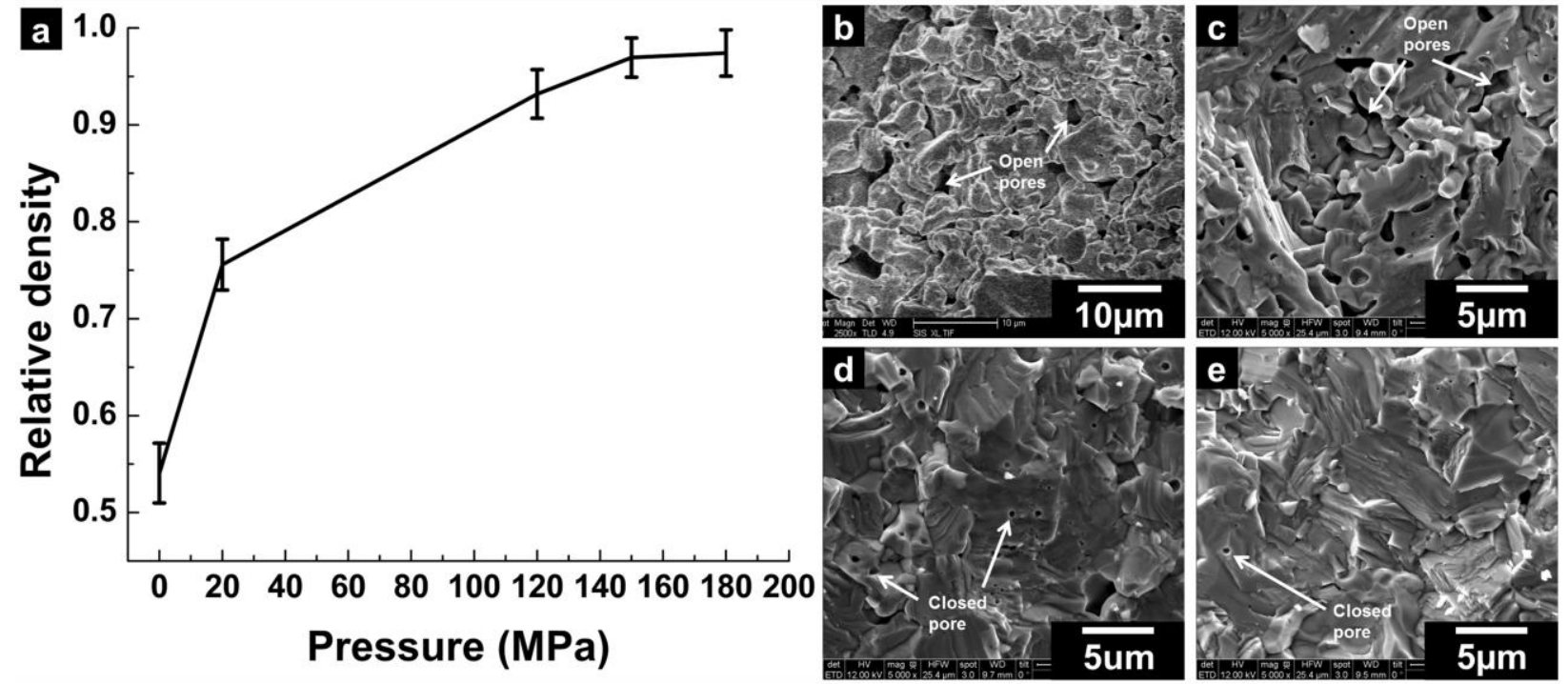

Fig. 13. Relative density variation with pressure at fixed maximum temperature of $1700^{\circ} \mathrm{C}$ (a) and SEM image of (b) $20 \mathrm{MPa}$, (c) $120 \mathrm{MPa}$, (d) $150 \mathrm{MPa}$ and (e) $180 \mathrm{MPa}$ for the $\mathrm{ZrN}$ (AA) consolidated by spark plasma sintering. Open and closed pores are indicated by white arrows. 


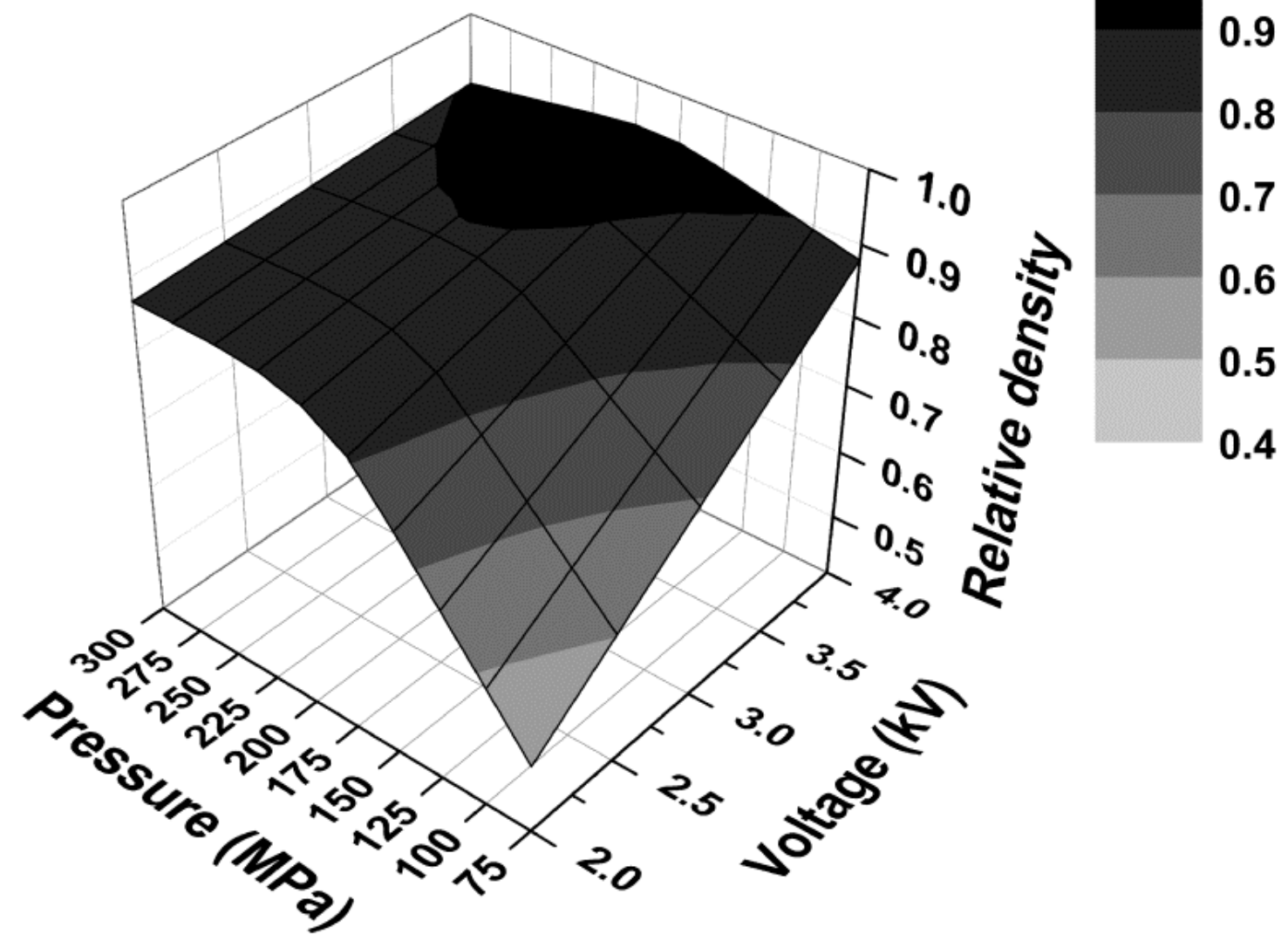

Fig. 14. The densification map of $\mathrm{ZrN}$ (AA) consolidated by high voltage electric discharge consolidation. The relative density of the specimens is given as a function of pressure and voltage. The legend indicates the relative density. 

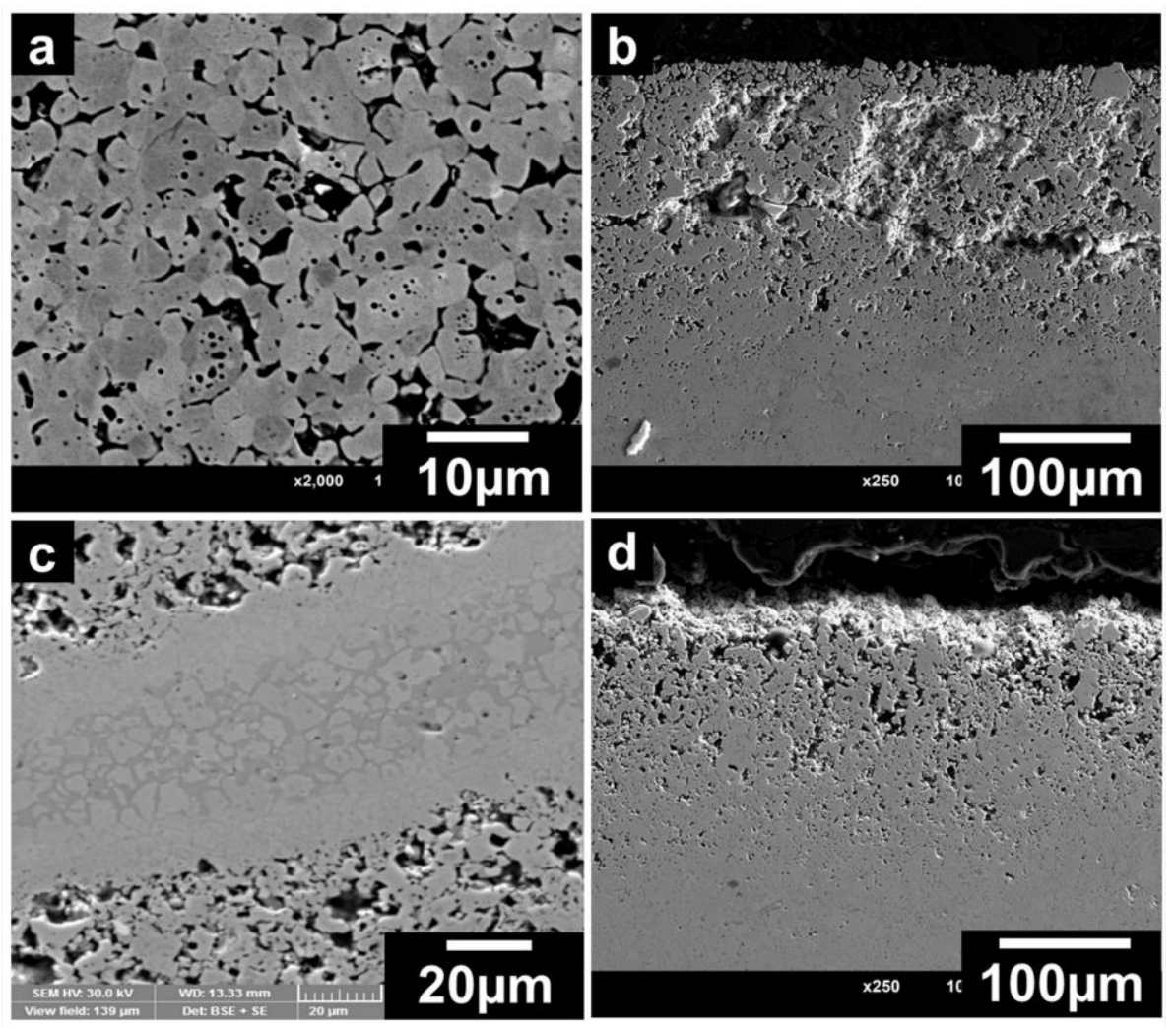

Fig. 15. Scanning electron microscope images of $\mathrm{ZrN}$ (AA) specimens consolidated by high voltage electric discharge consolidation. (a) central and((b) and (c)) edge of the specimen $(3 \mathrm{kV}$ and $175 \mathrm{MPa})$ and (d) edge of the specimen ( $3 \mathrm{kV}$ and $200 \mathrm{MPa})$. 


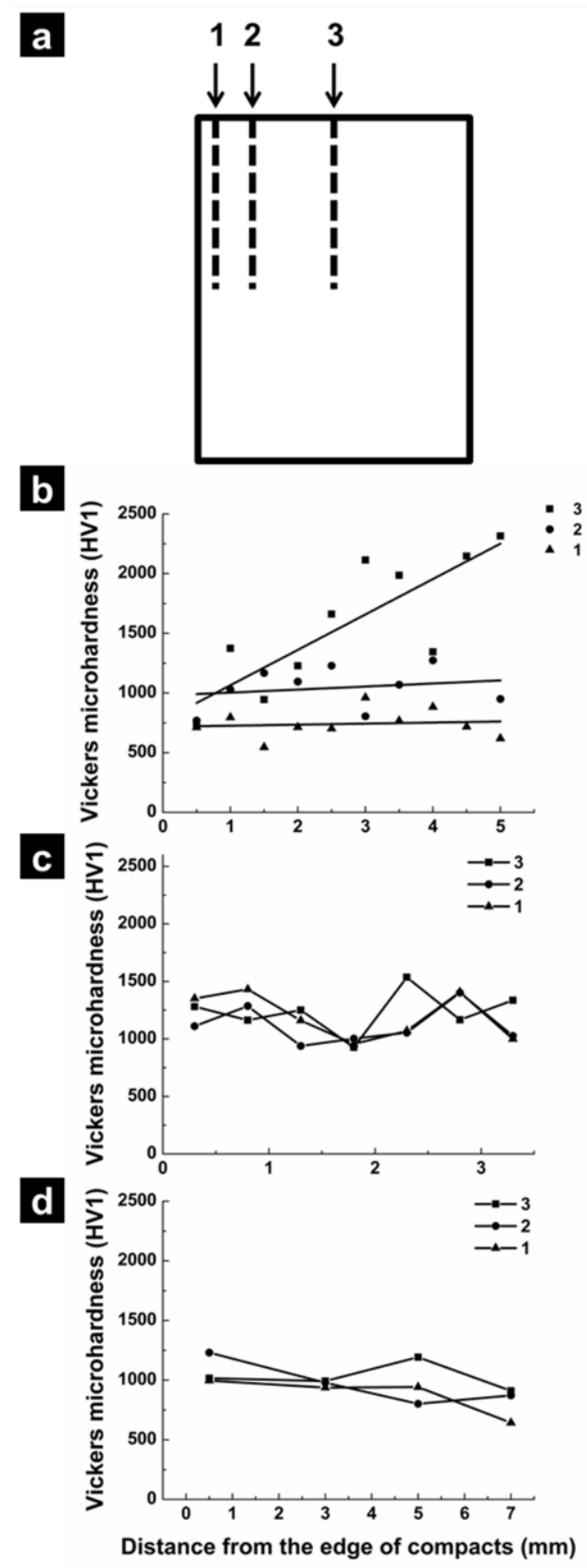

Fig. 16. Vickers micro-hardness results of $\mathrm{ZrN}$ specimens after sectioning, (a) schematics of the analyzed areas, from edge (Location 1) to center( location 3), Vickers micro-hardness plot as a function of the radial position of (b) AA specimen consolidated by high voltage electric discharge consolidation, (c) AA specimen consolidated by spark plasma sintering and (d) SA specimen consolidated by spark plasma sintering. 


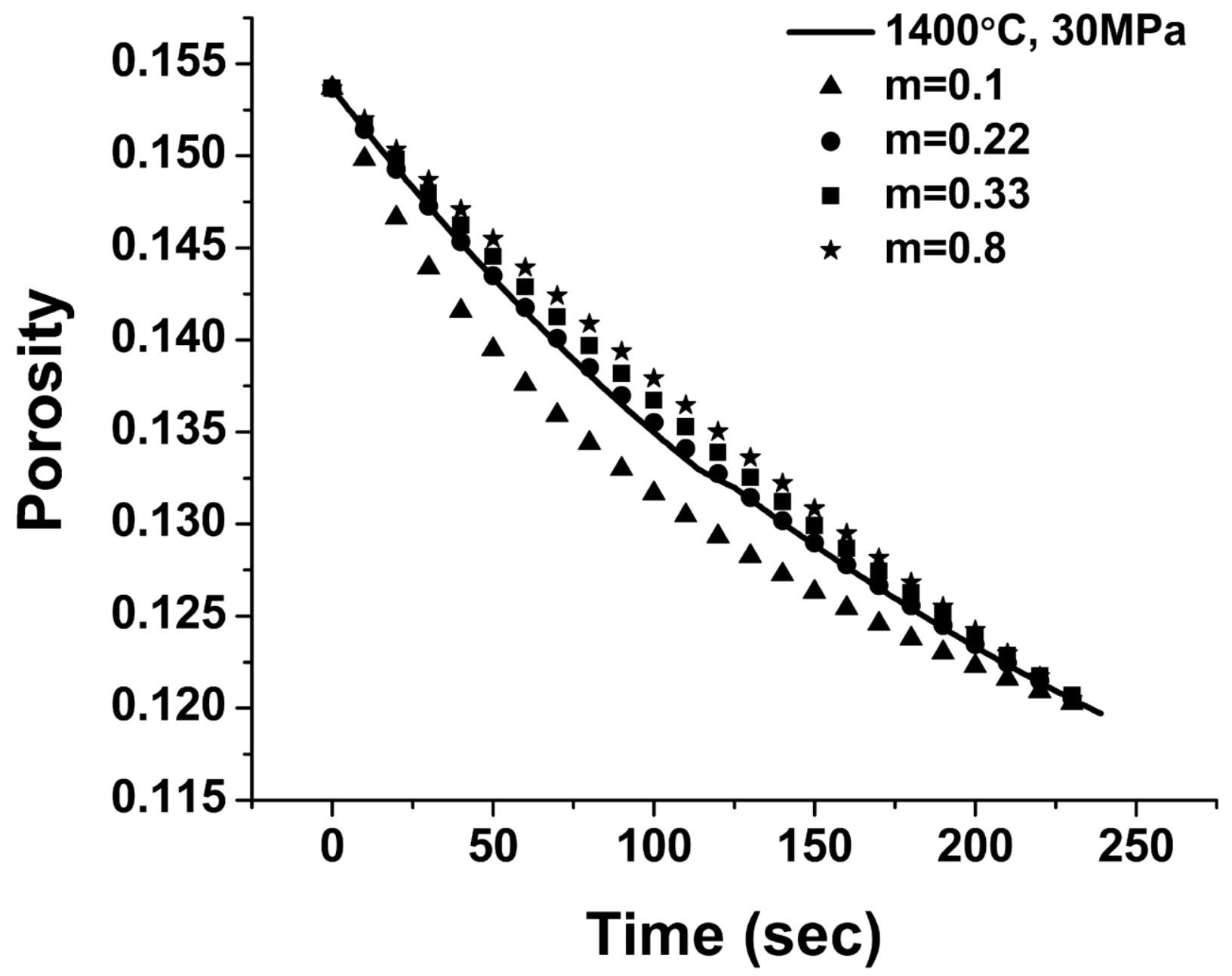

Fig. 17. Constitutive equation fitting of experimental porosity curves of $\mathrm{ZrN}$ (SA) specimen (SA1403) prepared by spark plasma sintering. 


\section{a}

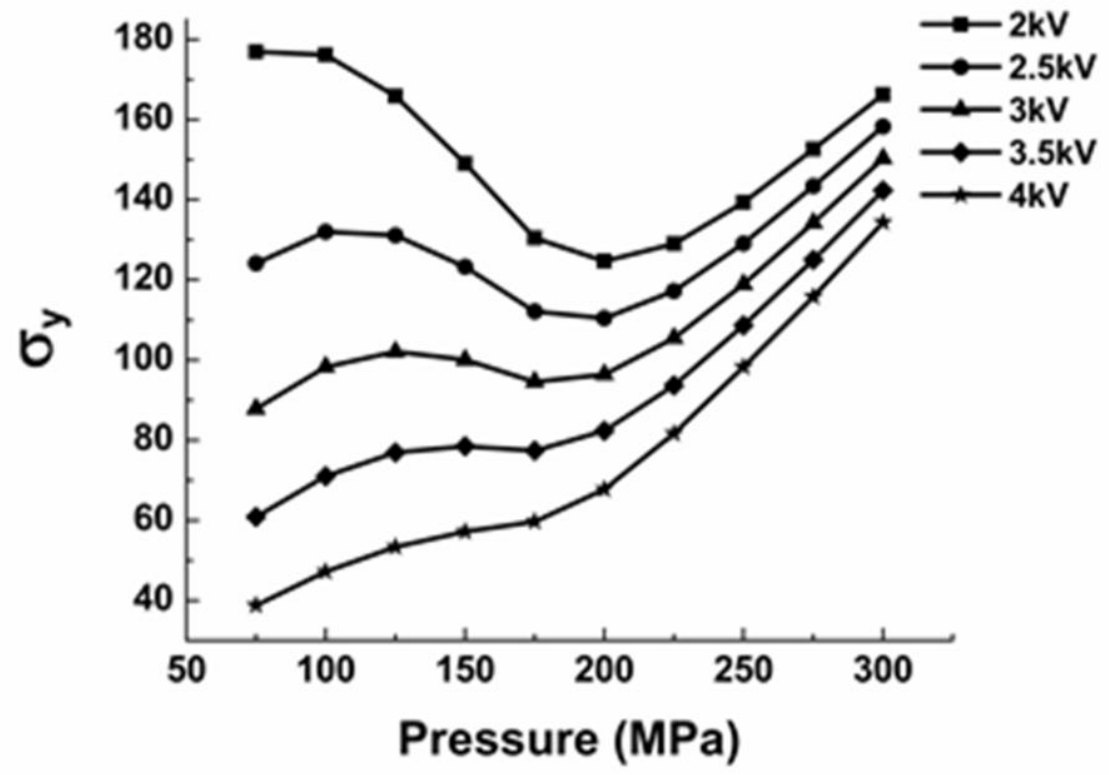

\section{b}

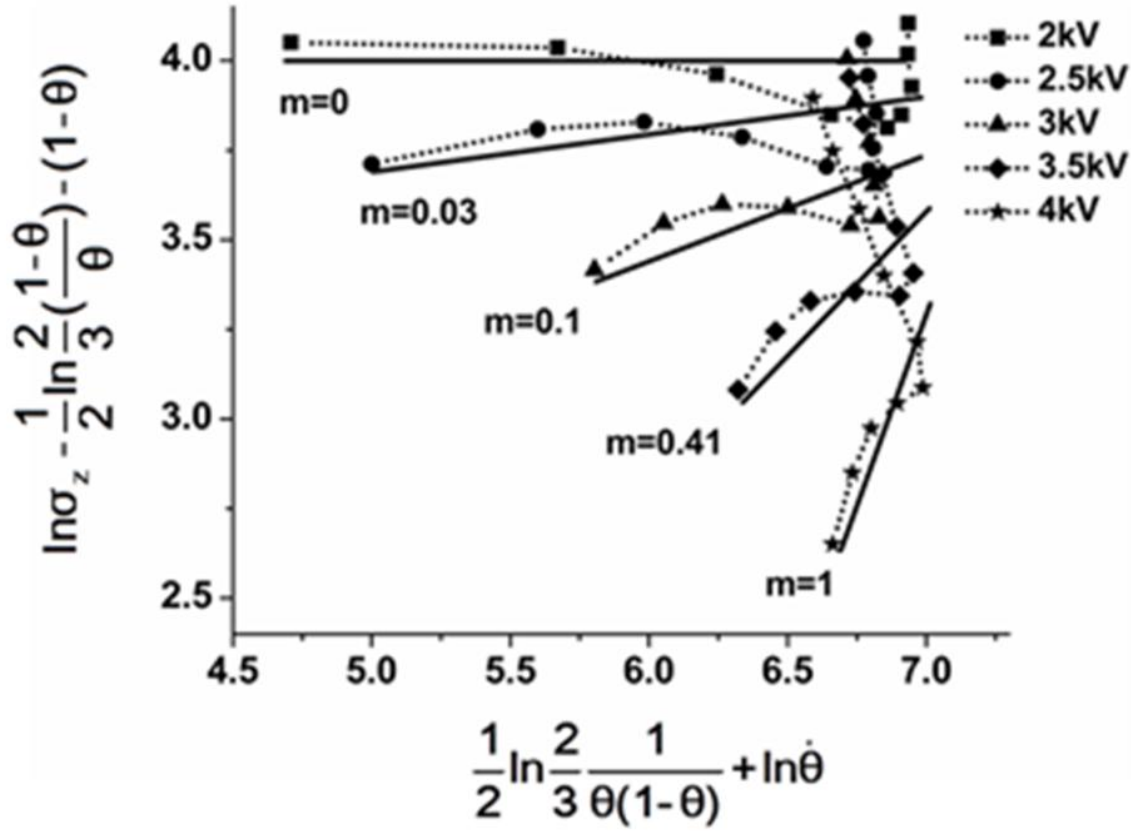

Fig. 18. Constitutive equation fitting of high voltage electric discharge consolidation results. (a) yield stress variation with pressure and (b) m variation with voltage. 